\title{
Persons with disabilities and their rights in the COVID-19 pandemic: leaving no one behind
}

\section{Introduction ${ }^{1}$}

Since March 2020, Latin America and the Caribbean has been facing a health, social and economic crisis caused by the coronavirus disease (COVID-19). The crisis has deepened pre-existing inequalities within countries, revealed the extent to which the most vulnerable groups in the population are excluded, and highlighted the urgency of including persons with disabilities in public policy actions taken in the short, medium and long term (ECLAC, 2020a and 2020b; ECLAC/PAHO, 2020).

There are around 70 million persons with disabilities in the region. They are one of the most excluded groups in society and are among the most affected by the pandemic. Before the health crisis, they were already less likely to participate in the community or to have access to health care, education or employment. A considerable proportion of them live in poverty and are exposed to higher rates of violence, neglect and abuse than the rest of the population. They are also among the most marginalized groups in communities in crisis situations.

Persons with disabilities are more severely affected by the attitudinal, environmental and institutional barriers that are perpetuated in the response to COVID-19. In addition, many have pre-existing health conditions that make them more susceptible to contracting the virus and they have more severe symptoms upon infection, leading to high mortality rates.

In this context, the international message to States must be reinforced, so that all actions concerning persons with disabilities are carried out with a rights-based approach, to ensure that no one is left behind, or left out of medium- and long-term post-pandemic strategies. Protection of their rights must be strengthened in line with the Convention on the Rights of Persons with Disabilities, the 2030 Agenda for Sustainable Development and the Montevideo Consensus on Population and Development. These instruments put persons with disabilities at the centre, as rights holders who must be involved in all stages of measures adopted by States, from planning and implementation to accountability

Up-to-date statistical information on persons with disabilities is in short supply in the region, and information on COVID-19 trends among this population group is even more scarce. There are no data disaggregated by disability, which makes analysis and decisionmaking difficult during this crisis and in subsequent recovery efforts.

This document examines the situation of persons with disabilities, in terms of the impact that COVID-19 could have, taking into consideration age and sex, health conditions, types of disability, access to basic infrastructure, overcrowding in the home, access to information and communications technology (ICT), employment status and education. In conclusion, the report presents some national actions that have been taken to reduce the impact of the pandemic and recommendations for addressing the devastating social and economic effects of COVID-19 on persons with disabilities.

The cut-off date for the information used to prepare this report is 30 September 2020, unless otherwise indicated.
Introduction

A. International instruments that protect the rights of persons with disabilities in situations of humanitarian risk

B. A sociodemographic overview of persons with disabilities in Latin America and the Caribbean, prior to the pandemic

C. Recommendations on public policy actions

Bibliography

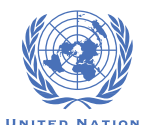

COVID-19 RESPONSE 


\section{A. International instruments that protect the rights of persons with disabilities in situations of humanitarian risk}

The SARS-CoV-2 virus arrived in Latin America and the Caribbean in March 2020. Several countries in the region became the epicentre of the pandemic, topping the global statistics of reported cases. According to a recent report by the Economic Commission for Latin America and the Caribbean (ECLAC) and the Pan American Health Organization (PAHO) "the pandemic has become an unprecedented economic and social crisis and, if urgent measures are not taken, it could transform into a food, humanitarian, and political crisis" (ECLAC/PAHO, 2020, p. 3).

In various regional forums on COVID-19, persons with disabilities have said that they are not being included in the strategies in response to the pandemic in their countries. Amid the pandemic in the region and the world, protection of the rights of persons with disabilities must be strengthened, not least because there is a binding international instrument and other international, global and regional instruments that call for this very action.

The Convention on the Rights of Persons with Disabilities, the 2030 Agenda for Sustainable Development and the Montevideo Consensus on Population and Development put persons with disabilities at the centre. Therefore, they must be involved in the entire process of designing and implementing public policies, as well as in accountability.

These instruments highlight the importance of States paying special attention to persons with disabilities in emergency situations, such as the ones the world and Latin America and the Caribbean in particular are now facing. Article 11 of the Convention on the Rights of Persons with Disabilities stipulates that States Parties must take "all necessary measures to ensure the protection and safety of persons with disabilities in situations of risk, including situations of armed conflict, humanitarian emergencies and the occurrence of natural disasters" (United Nations, 2006, p. 10). Therefore, as the COVID-19 pandemic affects the countries of the region, States must ensure that all necessary measures are taken to prevent persons with disabilities from contracting the virus, and in case of infection, that they have prompt access to health systems for treatment. In addition, States must implement economic and social support actions because the health crisis has hit all households and families in the region hard, especially the poorest and most vulnerable. However, actions aimed at households that include persons with disabilities should be more specifically tailored to the nature and severity of the disability.

Likewise, under article 25 of the Convention on the Rights of Persons with Disabilities, regarding health, the "States Parties recognize that persons with disabilities have the right to the enjoyment of the highest attainable standard of health without discrimination on the basis of disability". The same article underlines the importance of preventing "discriminatory denial of health care or health services or food and fluids on the basis of disability" (United Nations, 2006, p. 15). This is of particular importance under the current circumstances, in which instances of refusal of care have been reported, along with failures to prioritize access to beds in tertiary care centres for persons with disabilities. Today, more than ever, these rights must be respected, because no person with a disability should be left unattended amid this health crisis and States must do everything possible to prevent discrimination against them. Furthermore, article 28 of the Convention on the Rights of Persons with Disabilities, on an adequate standard of living and social protection, underscores the importance of States strengthening their measures and actions to ensure equal access to social protection programmes and for this right to be enjoyed without discrimination on the basis of disability (United Nations, 2006, p. 17). States must take appropriate measures to safeguard and promote the realization of this right. Goal 3 of the 2030 Agenda follows the same lines, stating that healthy lives must be ensured and well-being must be promoted for all at all ages. Although progress has been made in the region in these areas, the pandemic is a turning point that requires States to prepare for health emergencies, including allocating resources for their proper management. 
Having appropriate information on persons with disabilities has always been a great challenge in the countries of the region. International recommendations have been to improve data gathering in population censuses, specific surveys and records of persons with disabilities, because they have always produced undercounts. It has been a challenge for the countries to develop these measures with a social approach to disability, as recommended by the United Nations, the World Health Organization (WHO) and the Washington Group on Disability Statistics. These limitations of statistical instruments, which predated the pandemic, have become more evident as a result of the health crisis; no information has yet been published on infection rates by disability status or by the nature or severity of disability. An analogous situation exists for death rates: there are no records of how many persons with disabilities died from COVID-19. Article 31 of the Convention on the Rights of Persons with Disabilities, on statistics and data collection, indicates that States Parties shall collect appropriate information, including statistical and research data, to enable them to formulate and implement policies. Therefore, States should urgently include the disability status of infected and deceased persons in measurements of the pandemic in order to gather more information on how it is affecting persons with disabilities.

Sustainable Development Goal target 17.18 on data, monitoring and accountability calls for a significant increase in "the availability of high-quality, timely and reliable data disaggregated by income, gender, age, race, ethnicity, migratory status, disability, geographic location and other characteristics relevant in national contexts". The countries of the region have made efforts to meet this target (ECLAC, 2019c), but it has clearly not been achieved for persons with disabilities, and especially for statistical information on persons with disabilities and COVID-19. Such information has not yet been systematized in the countries and, if it exists, not everyone can access it. It is therefore impossible to perform the relevant analyses that would provide a robust statistical backing for designing actions and decision-making.

The repercussions of this dearth of data on persons with disabilities are multifarious. The morbidity and mortality of COVID-19 in persons with disabilities is unknown, which prevents specific prevention and containment measures from being taken for those who have contracted the disease. The lack of up-to-date data on persons with disabilities makes it difficult to meet their needs efficiently and effectively in crisis situations and also hinders medium- and long-term actions aimed at them. It is therefore urgent to have up-to-date information on this area.

\section{B. A sociodemographic overview of persons with disabilities in Latin America and the Caribbean, prior to the pandemic}

Around 70 million persons with disabilities live in Latin America and the Caribbean. This population group is very vulnerable to the health and social effects of the pandemic (ECLAC, 2020a).

Throughout history, persons with disabilities have been among the most disadvantaged groups in society. They have been systematically excluded from access to resources of all kinds and from recognition, and their opportunities to participate fully in economic, social, political and cultural life have been hindered (ECLAC, 2019a, 2018a and 2013a).

In general, poverty is more prevalent among persons with disabilities, and their educational attainment and labour inclusion are lower. The lower participation of children, adolescents and young persons with disabilities in formal education results in low educational attainment. This is also highly likely to hinder access to decent work that delivers a fair income and access to social protection, particularly for persons with certain types of disabilities that cause greater limitations (González and Stang, 2014; ECLAC, 2018a). Persons with disabilities frequently face access barriers to material resources, institutions, participation spaces, goods, rights or services that are fundamental for social life, and have little control over their own decisions (ECLAC, 2018b).

A recent ECLAC study on COVID-19 and persons with disabilities acknowledged that this population group experiences "multiple and simultaneous forms of discrimination on the
Persons with disabilities must not be left behind during the COVID-19 pandemic, nor must they be left out of medium- and long-term post-pandemic strategies. 
basis of socioeconomic status, gender, age, place of residence, ethnoracial status and migration status, among others" (ECLAC, 2020a, p. 1).

The relationship between disability and poverty is complex and one of interdependence. There is also evidence that it is one of the factors that explains the persistent exclusion of persons with disabilities. This relationship operates through various channels and at different levels, and disability is both a cause and, to a large degree, a consequence of poverty (ECLAC, 2018b). According to the World Health Organization (WHO, 2011, p. 11), persons with disabilities experience higher rates of poverty than persons without disabilities. In this regard, Meléndez (2019) states that there is a form of two-way link between poverty and disability: poverty increases the risk of disability and disability increases the risk of poverty.

Over the last two decades, several studies have shown unemployment and labour market exclusion to be among the main problems faced by the population with disabilities in the region, which lead to this population living in poverty. A high percentage of persons with disabilities in Latin America are unemployed or excluded from the labour force and differences in access to the labour market result in structural inequality (Stang, 2011). The study by González and Stang (2014), based on censuses from the early 2010s, showed that the panorama had not changed significantly. In the six countries analysed, a smaller proportion of persons with disabilities were in the economically active population than people without disabilities: the employment gaps for persons with disabilities ranged from $15 \%$ in Brazil to $31 \%$ in Uruguay. These data already revealed inequality and violations of rights, and were consistent with available information at the international level, which showed that participation in the labour force of persons with disabilities was significantly lower than for persons without disabilities (United Nations, 2009). The lack of accessibility to public thoroughfares and workplaces, discrimination, and the persistence of harmful stereotypes further undermine the low labour market participation of persons with disabilities. (ECLAC, 2018b).

The situation in the countries of the region is not unlike the rest of the world with regard to health service access for persons with disabilities, who are particularly vulnerable to deficiencies in services such as primary health care, rehabilitation, assistance, and support. Not all persons with disabilities receive the medical rehabilitation they need, few receive the assistive devices required, and not all of them have access to social welfare services. The cost of accessing health services and the lack of such services near their area of residence are reasons why persons with disabilities do not use health facilities (WHO, 2011).

The above shows that before the pandemic, persons with disabilities were already socially and economically disadvantaged compared to the rest of the population. This further accentuated the risks of infection and difficulties in dealing with the problems associated with the crisis.

The information analysed in this document comes from the population censuses of the countries in the region. This source of information was chosen primarily because it offers comparative advantages for studies on persons with disabilities, although in some cases the questions have certain limitations (ECLAC, 2019a). One of the advantages is that censuses are the only source of data with universal coverage; therefore, if the questions that gather information on this topic are well formulated, the results allow for estimation of the prevalence of disability in a country and the frequency of its various typologies. Censuses also allow information to be disaggregated at smaller geographical scales, which is important for local-level interventions. The broad sociodemographic characterization of persons with disabilities that can be achieved by comparing with other variables contributes to this. An international comparison also is possible if concepts, question structures and response categories are homogeneous (ECLAC, 2019a).

Although not all the countries of the region have conducted censuses in the 2010 round, a significant number (16) have, and of these countries, 15 have added questions to gather data on disability, helping to quantify the proportion of the population with disabilities (see figure 1). Around $14 \%$ of the Latin American population has some type of disability, 
a sizeable portion. ${ }^{2}$ The highest percentages are found in six countries, where persons with disabilities make up more than 10\% of the total population (Argentina, Brazil, Costa Rica, Dominican Republic, Peru and Uruguay); Guatemala and Honduras have the lowest percentages. This information on the proportion of persons with disabilities underscores the need to understand their sociodemographic characteristics, since they face enormous challenges in terms of access to spaces and to opportunities in education, health and decent work, even more so amid the crisis caused by the COVID-19 pandemic in the region.

Figure 1

Latin America and the Caribbean (15 countries): proportion of persons with disabilities, 2010 census round

(Percentages)

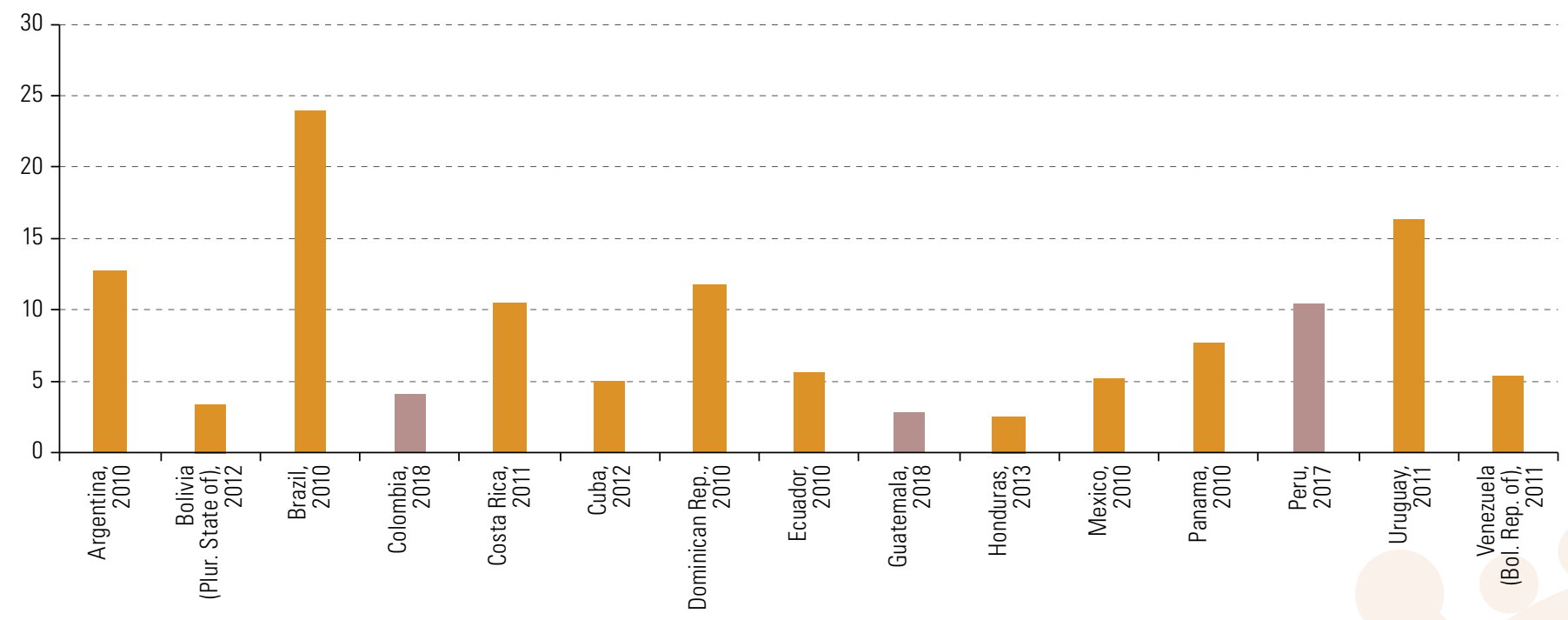

Source: Economic Commission for Latin America and the Caribbean (ECLAC), on the basis of census microdata from the respective countries processed with REDATAM

The most recent census information enables more up-to-date analysis of the situation of persons with disabilities when COVID-19 broke out in their countries, aiming to identify the main potential impacts of the pandemic on this population, given their sociodemographic status.

In the last three years, population censuses were conducted in four countries: Chile and Peru in 2017 and Guatemala and Colombia in 2018. In Chile, questions on disability were not included, as a more limited census was conducted. Therefore, information on persons with disabilities is available for Peru, Guatemala and Colombia. However, although the questions in the censuses of the three countries take into account the social approach to disability, there are certain differences that prevent full comparability. Box 1 describes how the information on disability was captured in the censuses of these three countries, as well as the methodological differences that affect the comparability of the results.

Caution is needed in aggregating these census data at the regional level, as methodological approaches differ from country to country, and only in some cases are different degrees of disability included 
Box 1

Measuring disability in censuses in Colombia, Guatemala and Peru

The international recommendations regarding measurement of disability in censuses provide a short set of questions on the following six domains: (i) difficulty seeing, even if wearing glasses; (ii) difficulty hearing, even if using a hearing aid; (iii) difficulty walking or climbing steps; (iv) difficulty remembering or concentrating; (v) difficulty with self-care, such as washing all over or dressing; and (vi) difficulty communicating in the usual language. The following four response categories are proposed: (i) cannot do at all; (ii) a lot of difficulty; (iii) some difficulty; and (iv) no difficulty.

The Washington Group on Disability Statistics recommends identifying as persons with disabilities those who choose answers (i) or (ii) in at least one of the domains. This information permits calculation of prevalence and participation levels for the purposes of international reporting and comparisons between countries (Washington Group on Disability Statistics, 2009 and 2017).

The Colombian census contained several questions, but these were not in line with international recommendations. The first one, a polar (yes-no) question, asked about the recommended domains, but not about assistive devices that mitigate the limitation either by eliminating it completely or by reducing the impact on daily life. If the answer was yes, respondents were asked a second question, which covered nine domains, including hearing and sight, but did not cover support from hearing aids or glasses, respectively. This could have resulted in overcounting of answers falling in response categories (i), (ii) and (iii) listed above. The next question also worked as a filter, as respondents were asked to identify which one of the nine domains affected them most in their daily life. The questionnaire then asked what had caused the difficulty in the domain selected in the previous question, and, lastly, what assistive devices were used to mitigate the difficulty. These extensive questions overloaded the questionnaire, breaking from the social approach to disability despite efforts to include it in the second question, and the results indicate that it was very likely that there was under- or overestimation of responses, as well as a higher number of nonrespondents.

The Guatemalan census used the six recommended domains and the four response categories that allowed for determination of the degree of limitation, but an age filter was applied, since it must be noted that the questions were asked with reference to people aged 4 and over. Although the questions proposed by the Washington Group on Disability Statistics allow for better data gathering when dealing with the population aged 5 and over as certain limitations can already be detected at that age, some limitations may be present from birth. Therefore, to avoid omitting that information, it is advisable not to apply an age filter, even though certain cognitive or psychosocial limitations only become evident later in life.

In the Peruvian census, the six recommended domains were used with wording that was very close to that of the recommendations, but the responses did not incorporate the different degrees of limitation. Therefore, while questions were in line with the social approach, the polar answers (yes-no) impaired collection of data on persons with disabilities and could lead to overestimation of that population, as respondents who would have chosen the third response category (some difficulty) but did not have that option may have answered yes.

In short, the Guatemalan census was closest to international recommendations. In Peru, a good effort was made in the wording of the questions, but not in the response categories. In the Colombian census, the inclusion of multiple filtering questions made the surveying more complex, meaning that its methodology was not fully in line with international recommendations. In Guatemala and Colombia, it was established that categories (i) "cannot do at all" and (ii) "a lot of difficulty" were the ones that determined the number of persons with disabilities. In Peru, a "yes" answer in at least one domain determined the number of persons with disabilities.

Source: Economic Commission for Latin America and the Caribbean (ECLAC), "Aspectos conceptuales de los censos de población y vivienda: desafíos para la definición de contenidos incluyentes en la ronda 2020", Seminars and Conferences series, No. 94 (LC/TS.2019/67), Santiago, 2019; Washington Group on Disability Statistics, The Washington Group Short Set on Functioning: Question Specifications, Washington, D.C., 23 October 2017 [online] https://www.washingtongroup-disability.com/fileadmin/uploads/wg/Documents/Events/17/ WG-Document-4-The-Washington-Group-Short-Set-on-Functioning-Question-Specifications.pdf; and Understanding and Interpreting Disability as Measured using the WG Short Set of Questions, Washington, D.C., 20 April 2009 [online] http://www.cdc.gov/nchs/data/ washington_group/meeting8/interpreting_disability.pdf. 


\section{Structure by age and sex}

Table 1 shows the proportion of persons with disabilities in the three countries analysed. The highest proportion is in Peru, where around 10\% of the population has some type of disability. In Colombia, the percentage is around $4 \%$ and in Guatemala it is no more than 3\%. In Peru and Guatemala, there are higher proportions of persons with disabilities in urban areas than in rural areas; in Colombia, in contrast, the opposite is true, with a slightly higher proportion in the rural areas.

Table 1

Colombia, Guatemala and Peru: proportion of persons with disabilities by area of residence, 2017 and 2018

(Percentages)

\begin{tabular}{lccc}
\hline & Country total & Urban & Rural \\
\hline Perú, 2017 & 10.4 & 10.7 & 8.8 \\
\hline Guatemala, 2018 & 2.8 & 3.0 & 2.5 \\
Colombia, 2018 & 4.1 & 3.8 & 4.9 \\
\hline
\end{tabular}

Source: Economic Commission for Latin America and the Caribbean (ECLAC), on the basis of census microdata from the respective countries processed with REDATAM.

The population structure by age and sex shows that a higher proportion of persons with disabilities are found in the middle and older age groups of the population pyramids (see figure 2). In Colombia, less than $10.6 \%$ of all persons with disabilities are under 18 years of age, while $46 \%$ are aged 60 or over. In Guatemala, $15 \%$ of persons with disabilities are under 18 and $44 \%$ are 60 or over. Persons with disabilities in Peru are mainly older people: $40 \%$ are 60 or over, while $14 \%$ are under 18 . The age structure of persons with disabilities is quite different from that of persons without disabilities: the structure of the latter is rather young, with a pyramid that is wider at the base and in the 18-29 age group.

The fact that persons with disabilities have an older demographic structure suggests that comorbidity for this population group is typical of older ages, which may or may not be related to their type of disability, but which would lead to more severe cases of COVID-19 in people who are infected, since the virus exacerbates pre-existing health problems and increases the likelihood of dying among older persons (WHO, 2020b).

There is a higher prevalence of disability among women: the masculinity ratio is 87 men per 100 women in Colombia, 92.2 per 100 in Guatemala and 76 per 100 in Peru. Differentiating by age group, the predominance of women is even more pronounced at older ages, especially in the 80 and over group, with ratios of 64, 85 and 77 men per 100 women in the three countries, respectively. The fact that women outnumber men is widely noted in previous studies conducted with census data from other countries in the region. Gonzalez and Stang (2014, p. 83) mention that one key characteristic is that the masculinity ratio for people with at least one disability is systematically below 100 , meaning that there is a higher proportion of women. They also note that a recent study indicated that disabilities were more prevalent among women than men in more than half of the countries in the region. Gonzalez and Stang add that the same study found that this was more evident from the age of 60 onward, as the longer life expectancy of women increases the possibility of having a disability linked to a chronic illness or an accident in the later stages of life. 
Figure 2

Colombia, Guatemala and Peru: proportion of persons with and without disabilities in total population by age group and sex, 2010 census round

(Percentages)

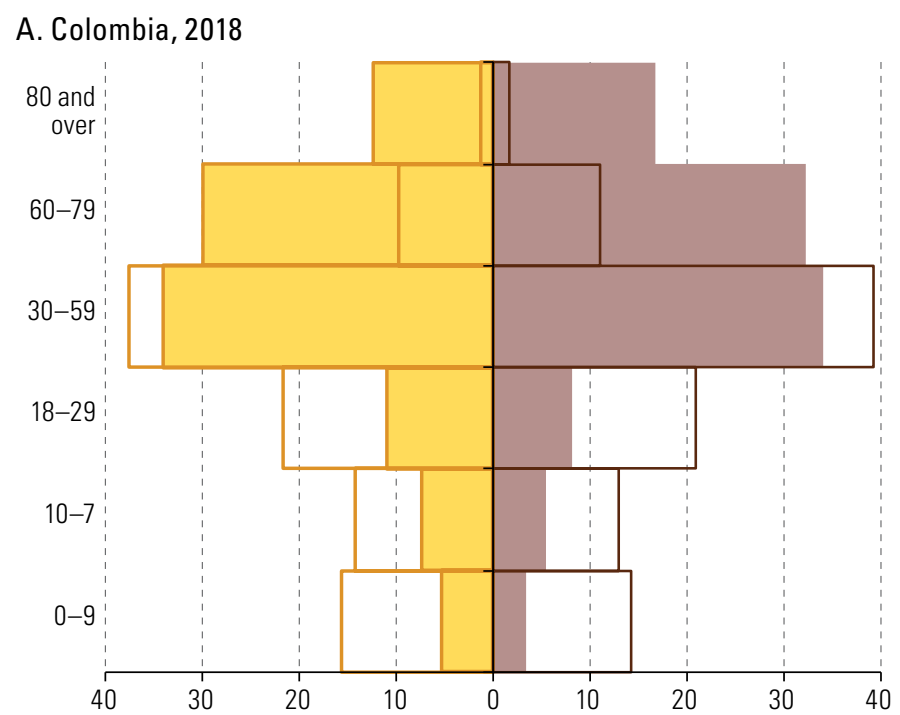

\section{B. Guatemala, 2018}

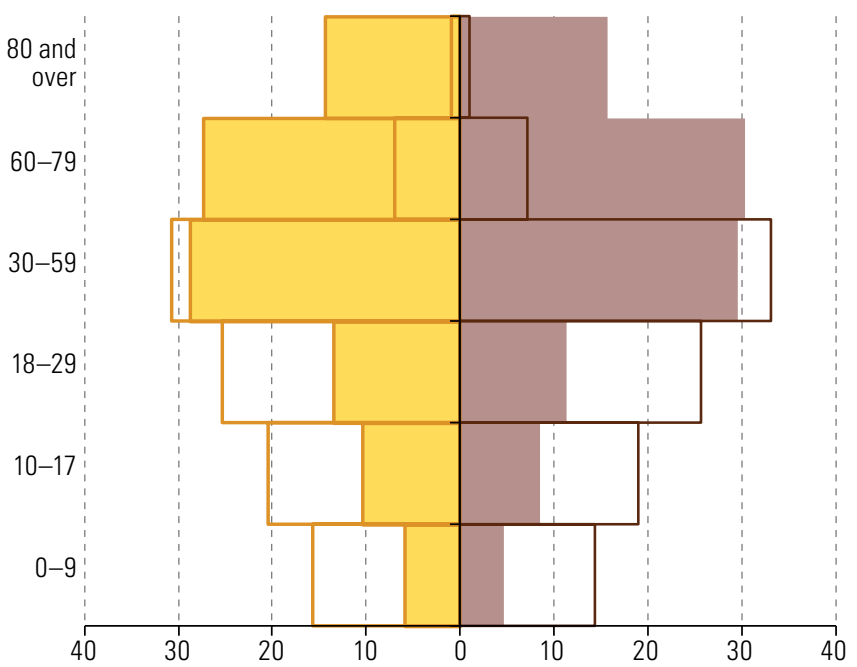

\section{Peru, 2017}

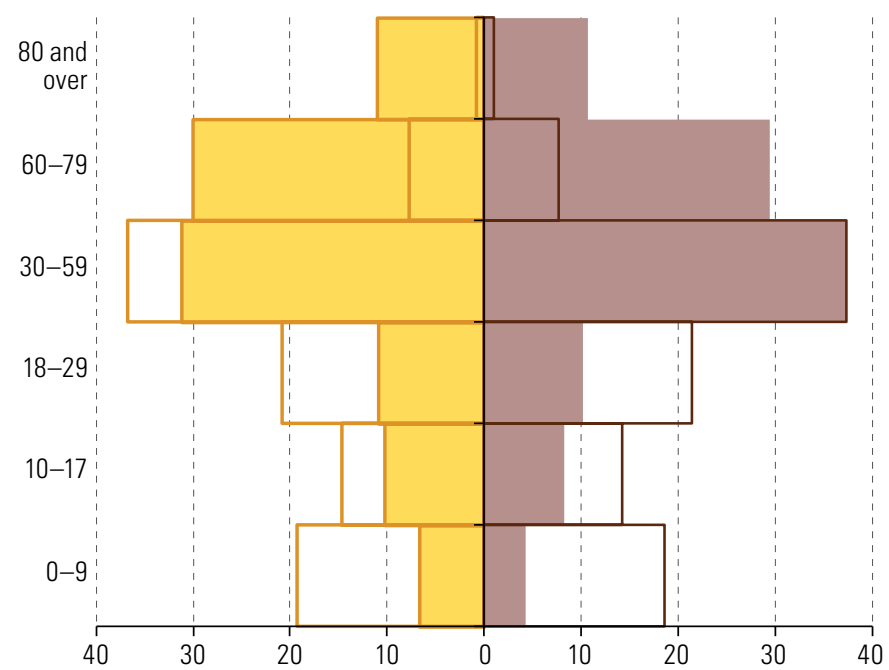

Men, with disabilities

Women, with disabilities

Men, without disabilities

Women, without disabilities

Source: Economic Commission for Latin America and the Caribbean (ECLAC), on the basis of census microdata from the respective countries processed with REDATAM.

It is essential, when carrying out actions for persons with disabilities in response to the pandemic, to consider the gender perspective and the type of disability, as these aspects will determine what safeguards should be put in place to prevent infection and to protect people who have contracted the disease.

As noted, the three countries studied partly take into account the six domains recommended for inclusion by the Washington Group on Disability Statistics. In some cases, even more domains were included. It is therefore possible to analyse and compare several of them. Figure 3 shows the proportion of persons with disabilities according to the type of limitation. In all three countries, people who have visual limitations even if they wear glasses account for the highest percentage. In fact, $48 \%, 27.7 \%$ and $24 \%$ of persons with disabilities in Peru, Guatemala and Colombia, respectively, reported this limitation. The second highest proportion corresponds to persons with limitations on movement or walking (around 
20\% in the three countries). The third highest corresponds to people who have difficulty hearing even when using a hearing aid: $14.7 \%$ of persons with disabilities in Guatemala and $13.2 \%$ in Peru reported having this limitation, while in Colombia (9.4\%) it is the fourth highest proportion. Another common domain in all three countries is difficulty interacting with others: the highest percentage of people with this limitation is found in Guatemala (14.4\%), while in Colombia and Peru the percentage is very similar (around 5.5\%). With regard to difficulty understanding, $11.7 \%$ of persons with disabilities in Guatemala reported this limitation, while in Colombia and Peru the percentages were $9.7 \%$ and $8.2 \%$, respectively. In Peru and Colombia, speech difficulties were surveyed, and less than $10 \%$ of persons with disabilities were found to have this limitation (5\% in Peru and $7 \%$ in Colombia).

\section{Figure 3}

Colombia, Guatemala and Peru: proportion of persons with disabilities by type of limitation, 2010 census round

(Percentages)

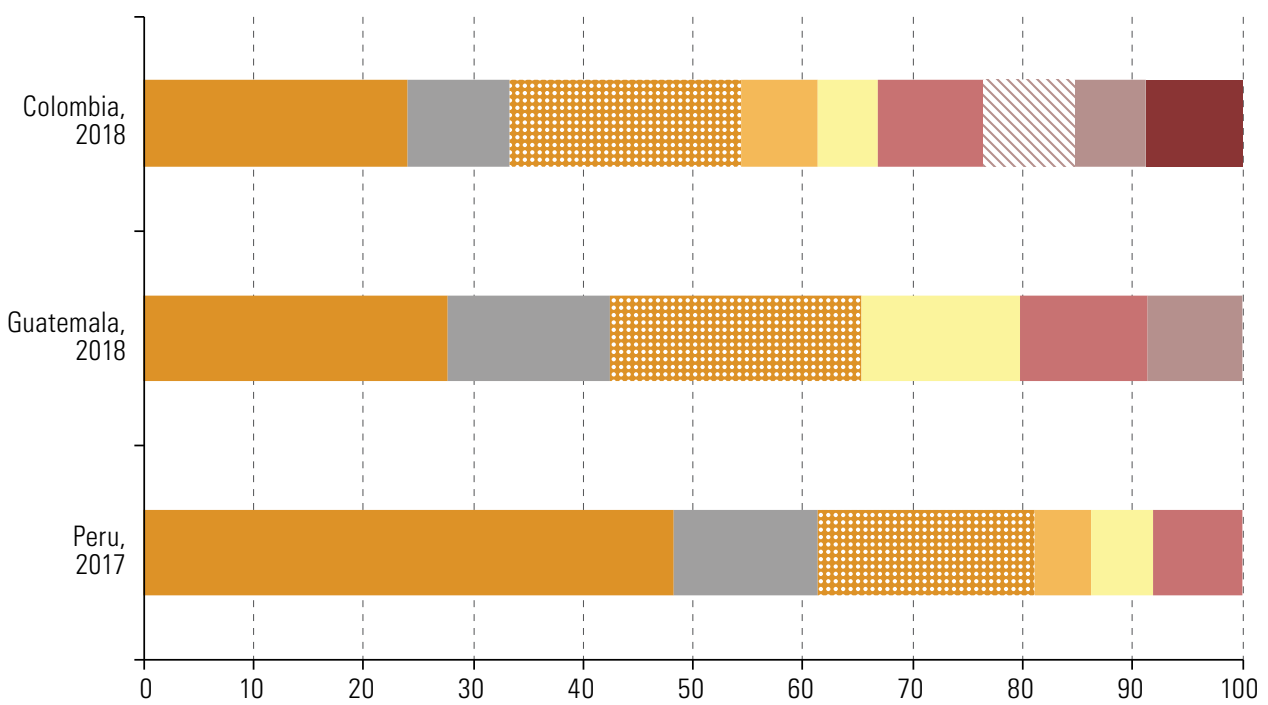

Seeing

Hearing

醋 Moving or walking

Speaking

Interacting with others

Understanding

'Nripping or picking up objects

Eating, dressing

Respiratory and cardiac deficiencies

Source: Economic Commission for Latin America and the Caribbean (ECLAC), on the basis of census microdata from the respective countries processed with REDATAM

For limitations on self-care tasks, such as eating, dressing, or holding things, the percentages are close to $8 \%$ in Colombia and Guatemala: this domain is important because it is a proxy for the number and proportion of people who need support to perform everyday activities and therefore require daily care. Colombia surveyed respiratory and cardiac deficiencies, a domain that is not included in the recommendations of international bodies since it is, strictly speaking, a medical condition. However, amid the current pandemic caused by a virus that attacks the respiratory and cardiac systems, it is of interest to include this category, which accounted for $8.8 \%$ of persons with disabilities in Colombia.

There are significant gender differences in terms of the type of limitations experienced by persons with disabilities. For example, difficulties seeing even when wearing glasses and difficulties moving and walking are more prevalent among women, while difficulty hearing even when wearing hearing aids is the most prevalent limitation among men, followed by difficulty moving and walking.

WHO believes that persons with disabilities may be at greater risk of contracting COVID-19 owing to several factors, which are more significant the higher the prevalence of some limitations. For example, application of basic hygiene measures, such as hand washing, may be more difficult for people who have difficulty gripping or picking up objects, or who have difficulty rubbing their hands together. Moreover, people who have difficulty moving or walking and must use a wheelchair or other assistive devices and who do not have physically accessible toilets or hand washing facilities will have more obstacles to overcome to implement recommended hygiene measures.
Persons with disabilities have an older population structure, which could lead to more complex cases of COVID-19. 
Another important factor is the difficulty persons with disabilities have in maintaining physical distancing if they need additional support to perform everyday activities or if they are institutionalized. Also, people who are blind or visually impaired and who need to touch objects to obtain information about their surroundings or who must physically support themselves in frequently used spaces will be at greater risk of contracting the virus. Indeed, no matter the limitation, any barriers that persons with disabilities may have in accessing public health information, and in particular information on COVID-19, will increase the risk of infection (WHO, 2020b).

Some persons with disabilities have underlying comorbidities or health disorders and may be at greater risk of developing more severe cases of COVID-19 if they become infected. This is because the virus exacerbates existing health problems, particularly those related to respiratory functions, the immune system, heart problems and diabetes (WHO, 2020b). In addition, persons with disabilities may face barriers in accessing health care, partly because of increased demand for these services in the pandemic or because other population groups are given priority for assorted reasons. It is in this context that, as the pandemic spread and particularly when it intensified in some countries of the region, the Committee on the Rights of Persons with Disabilities and the Special Envoy of the Secretary-General on Disability and Accessibility issued communiqués calling on States to take all appropriate measures to ensure access to health services for persons with disabilities and to provide them with the same range, quality and level of medical care as other persons, including mental health services. Moreover, persons with disabilities who contract the coronavirus will always have the right to be treated with dignity, to make decisions with autonomy, to have their wishes and preferences respected, to have their free and informed consent requested, and to have the privacy of their personal data protected. This should be done taking into account especially articles 10, 25 and 28 of the Convention on the Rights of Persons with Disabilities, the 2030 Agenda for Sustainable Development, in particular Goal 3 on health and well-being, and several priority actions of the Montevideo Consensus on Population and Development.

\section{Households and families that include persons with disabilities}

Another way to analyse disability is to go beyond the individual and examine households and families that include persons with disabilities, since it is from there that they interact, either within their own family group or with society. It is also important to consider the situations that occur in a household when one or more members have a disability, as the support and care provided will depend on the type of household or family. Likewise, gender differences should not be lost sight of, as they are relevant at the family level: the roles of men and women are not the same throughout their life cycles, or in the household or family. The burden of care and support provided to persons with disabilities within the home is usually borne by women, whether they are the mothers, daughters or partners of these persons. And, in this context of a health crisis, the burden of care and household tasks can increase significantly for women.

Table 2 shows that the proportion of households with at least one person with a disability is highest in Peru (26\%), while in Guatemala the proportion is 14\% and in Colombia it is 10\%. Although in the latter two countries the proportion is less than $15 \%$ of households, it is clear that the impact of disability is greater at the household level than at the individual level.

Table 2

Colombia, Guatemala and Peru: proportion of households with persons with disabilities, 2010 census round

(Percentages)

\begin{tabular}{ll}
\hline Guatemala, 2018 & 14.2 \\
\hline Colombia, 2018 & 10.4 \\
\hline Perú, 2017 & 26.3 \\
\hline
\end{tabular}

Source: Economic Commission for Latin America and the Caribbean (ECLAC), on the basis of census microdata from the respective countries processed with REDATAM. 
When disability is considered from the perspective of households and families, the population group made up of persons with disabilities has an even greater impact on society, since the home and the family are the spaces where most of people's lives take place (Pérez, 2016). There are a wide variety of family situations: people can choose to live alone, in couples without children, in single-parent homes, in domestic partnerships or in same-sex unions with children (Arriagada, 2007). However, it is less clear whether persons with disabilities have the same freedom to make these decisions, even though they have the right to live an independent life.

Information on the structure of the households and families of persons with and without disabilities can be used to determine what specific needs arise in these family situations when there are persons with disabilities, and thus to include specific social policies. ${ }^{3}$ Figure 4 shows the relative distribution of the family situation of households with and without persons with disabilities in the three countries analysed. There are several similarities and some differences between the two types of households. Firstly, regardless of whether or not there are any persons with disabilities, households made up of two-parent nuclear families are most prevalent. However, among households without persons with disabilities, this structure accounts for the highest proportion: 53\% in Guatemala, and 43\% in Colombia and Peru. Among households with persons with disabilities, the proportion of two-parent nuclear families is lower, and that of extended families with two parents and relatives is the second most frequent situation. Together, these two categories represent more than half of the households with persons with disabilities: 63\% in Guatemala, 52\% in Colombia and 53\% in Peru. This indicates that persons with disabilities live in nuclear and extended families because of the support and care that they need in everyday activities. However, although the proportion of single-person households is higher among households without persons with disabilities, it is particularly significant that around 10\% of households whose members include persons with disabilities are single-person.
In households with persons with disabilities there is a greater demand for support and care during the health crisis and an increased burden of these tasks for women.

Figure 4

Colombia, Guatemala and Peru: structure of households with and without persons with disabilities, 2010 census round (Percentages)

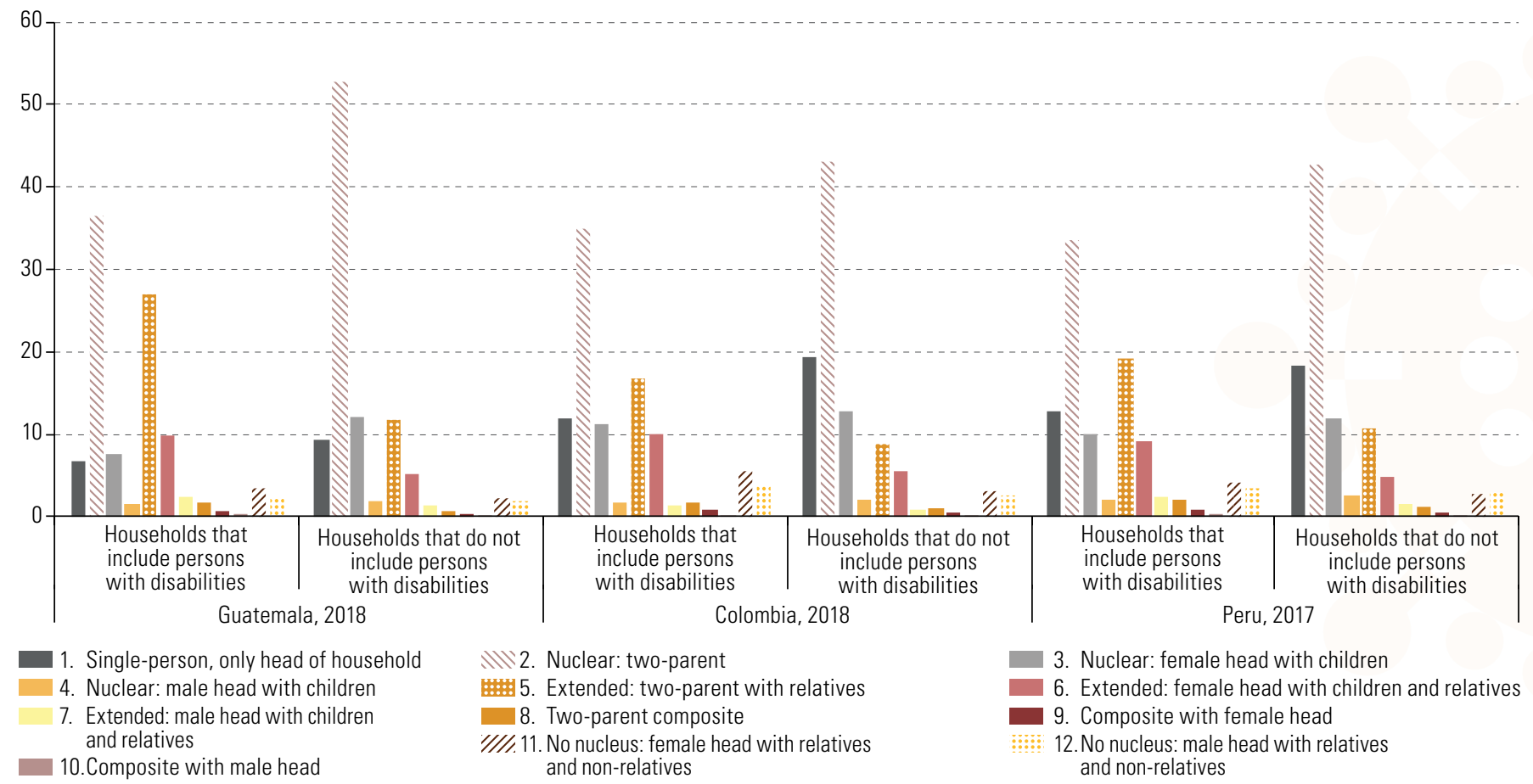

Source: Economic Commission for Latin America and the Caribbean (ECLAC), on the basis of census microdata from the respective countries processed with REDATAM.

\footnotetext{
The typology of the household structure is based on the kinship of the members of a household with respect to the person who declares him or herself to be the head of the household. Two main types of units are established: non-family households and families. Non-family households include single-person households and those without a marital nucleus or paternal or maternal bond, with or without other relatives. Families include nuclear families (only nuclear members), extended families (with other relatives) and composite families (with non-relatives). Each of these structures can be, in turn, single- or two-parent.
} 
In this health crisis, and with the physical confinement measures implemented in the countries to curb the spread of the virus, persons with disabilities, particularly those living alone, may face situations in which their rights are infringed (ECLAC, 2020a). Access to essential goods and services that maintain well-being can be impeded; this is especially critical in the case of health, rehabilitation and care services, but also in the case of medicines, diapers, assistive devices and special foods, among other goods (ECLAC, 2020a). In addition, care relationships may be suspended or interrupted, and support networks weakened or truncated by the strict lockdowns in countries. If a person with a disability becomes infected and has severe symptoms of the disease, they will need support and care; without accessible technologies to communicate with friends or relatives, this support may be delayed or not arrive when they need it.

Women are heavily involved in care and, in households where there is a person with a disability who requires daily care, it is mainly women who provide it. Before the pandemic, this care could be distributed between formal arrangements (educational and care centres, care centres for dependent persons, paid domestic work) and informal arrangements (such as support from family members and neighbours). However, physical confinement and distancing measures during the pandemic have led to the reduction of discontinuation of such arrangements, putting more pressure on women caregivers and exponentially increasing their workload, with an unequal burden that is mainly borne by women (ECLAC, 2020c).

In economic and care terms, households with persons with disabilities are under greater pressure. In these households there are more health, rehabilitation and education expenses, as well as higher spending on buying and maintaining assistive devices and on medicines and transport (ECLAC, 2020a). Furthermore, to meet the aforementioned care needs, some members of households may be forced to give up their paid work, and it is often women who withdraw from the labour market. This affects household income, which has already been hit by the economic crisis in the countries of the region, potentially aggravating poverty if States do not put support mechanisms in place to cover or subsidize the costs and needs of these households (ECLAC, 2020a).

\section{Overcrowding and access to basic services}

Since the beginning of the pandemic, the recommendations from WHO and countries' ministries of health have mainly been for people to wash their hands frequently with soap and water, maintain a physical distance of at least 1 or 2 metres from others, avoid touching their eyes, nose and mouth, and wear a mask in open or closed public spaces.

In order to comply with these prevention measures, the population must have access to drinking water in their homes for frequent hand washing and for washing and disinfecting food and other objects entering the home. Therefore, access to drinking water is a fundamental requirement and, although it has always been, in this context it is even more imperative. Persons with disabilities must have access within the home, with barrier-free accessibility to bathrooms or washbasins.

The First regional report on the implementation of the Montevideo Consensus on Population and Development (ECLAC, 2019b) and the Quadrennial report on regional progress and challenges in relation to the 2030 Agenda for Sustainable Development in Latin America and the Caribbean (ECLAC, 2019c) state that access to drinking water has increased in most countries, and that significant efforts have been made to increase coverage; however, this work has been insufficient, as gaps between urban and rural areas remain. Nonetheless, at the time these reports were prepared, more than $90 \%$ of the population in Latin America and the Caribbean used improved drinking water sources.

In the three countries analysed, there are almost no differences in access between people with and without disabilities. Nonetheless, there are differences between urban and rural areas, whereby persons with disabilities in urban areas have more access to drinking water than their rural counterparts. As figure 5 shows, there are considerable gaps. In Colombia, while $5.6 \%$ of persons with disabilities in urban areas do not have access to drinking water, almost 38\% do not in rural areas. In Guatemala, 25\% of persons with disabilities in urban areas do not have access to drinking water within the home, while $61 \%$ do not in rural areas. In Peru, around 10\% of persons with disabilities in urban areas do not have access to drinking water within the home, and $28 \%$ in rural areas. 
Figure 5

Colombia, Guatemala and Peru: proportion of population without access to drinking water within the dwelling by disability status and area of residence, 2010 census round

(Percentages)

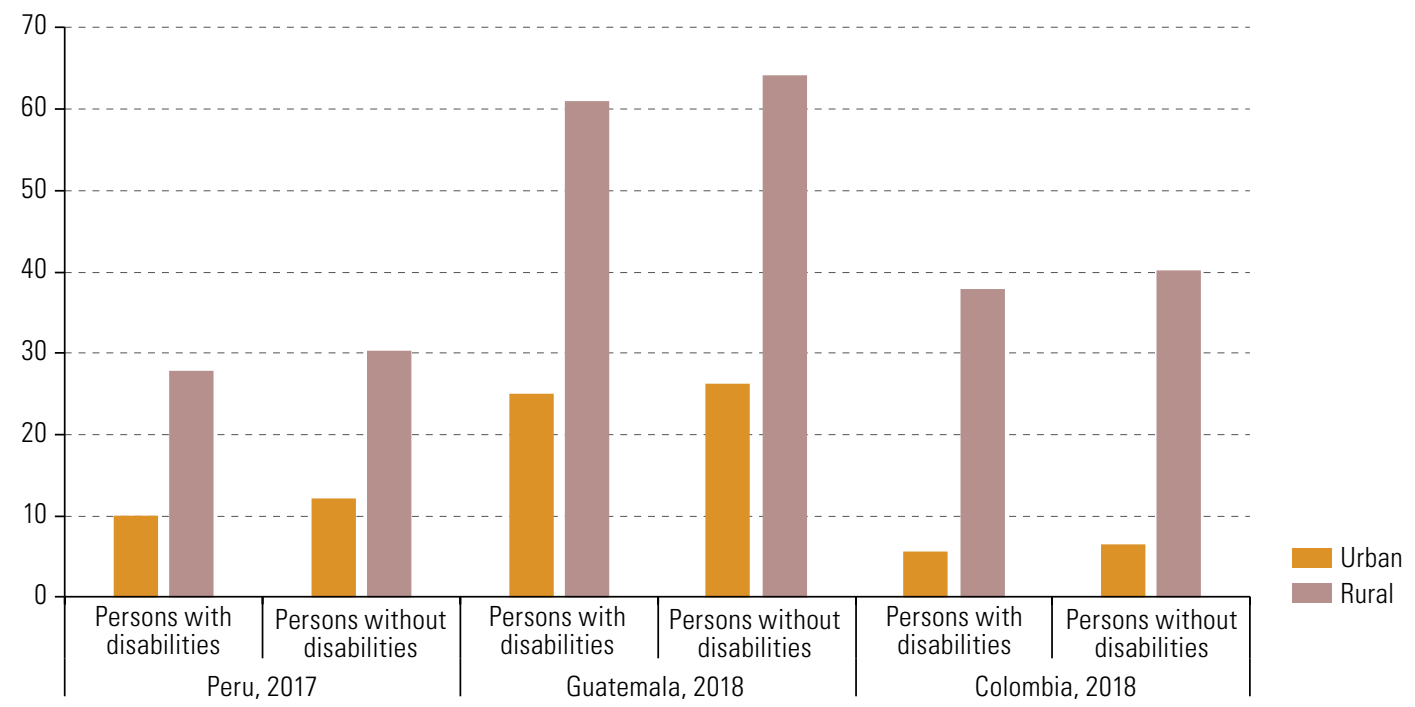

Source: Economic Commission for Latin America and the Caribbean (ECLAC), on the basis of census microdata from the respective countries processed with REDATAM.

While these figures indicate that there is virtually no difference in access to drinking water between persons with and without disabilities, when there is no access within the home, persons with disabilities have more difficulty in implementing the recommendations on frequent hand washing and cleaning and disinfection of their homes and food, as they face more barriers to alternative means of obtaining the drinking water they need. A United Nations report on Goal 6 (ensuring the availability and sustainable management of water and sanitation for all) indicates that people without access to drinking water will have more difficulty safeguarding their health and well-being, as COVID-19 is unlikely to be eliminated without access to drinking water. Therefore, the effects on persons with disabilities could be considerably more severe in urban areas if they do not have access to drinking water, as infection rates are higher in cities.

A recent ECLAC report (2019b, p. 165) states that "basic sanitation is the service which reflects the most limited coverage in the region", although there are also gaps between urban and rural areas. The percentage of households with access to sanitation is just under $70 \%$ in urban areas, compared with 53\% of households in rural areas (ECLAC, 2019b).

The trends are similar in the three countries for access to sanitation within homes, in that there are virtually no gaps in access between people with and without disabilities (see figure 6). The proportion of the population without access to this service is lowest in Colombia, with less than 10\%. In Guatemala, this proportion is $48 \%$ and in Peru it is around 33\%. At the national level there are very significant gaps between urban and rural areas. About $30 \%$ of the rural Colombian population has no access to sanitation, while in urban areas the percentage is just 2.5\%. The proportion of the population without access in rural areas of Guatemala is greater (over $72 \%$ ), whereas in urban areas the percentage is $25 \%$. In Peru, the percentage is over $85 \%$ in rural areas and is around $20 \%$ in urban areas.

It is important to have high coverage in both urban and rural areas because "sanitation is considered one of the inherent uses of water and access to it is not only fundamental to human dignity, but also to protecting the quality of water resources" (ECLAC, 2019b, p. 165; Bautista, 2013). For persons with disabilities, having access to sanitation during the COVID-19 pandemic allows for improved hygiene in the places where they live. Untreated and contaminated wastewater makes it more difficult to maintain a clean and hygienic environment to help protect against infection. 
Figure 6

Colombia, Guatemala and Peru: proportion of population without access to sanitation within the dwelling by disability status and area of residence, 2010 census round

(Percentages)

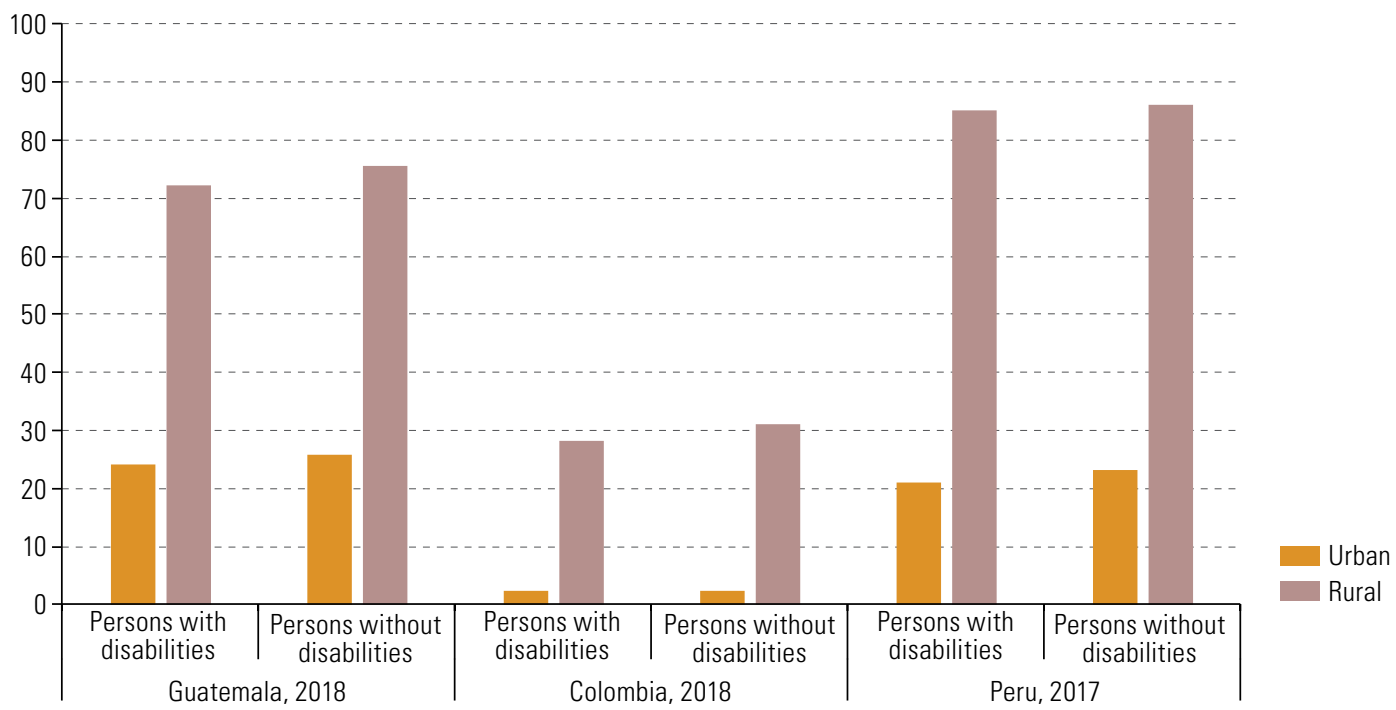

Source: Economic Commission for Latin America and the Caribbean (ECLAC), on the basis of census microdata from the respective countries processed with REDATAM.

If the homes of persons with disabilities have access to basic services (water and sanitation) and there is limited overcrowding, the risk of infection tends to be lower.
Access to drinking water and sanitation are basic human rights. Bautista (2013) states that water and sanitation, in particular, are rights in themselves (human right to water and sanitation) and are essential to the fulfilment of all human rights, especially the right to housing and to health. In this regard, article 28 of the Convention on the Rights of Persons with Disabilities, on an adequate standard of living and social protection, requires States Parties to "ensure equal access by persons with disabilities to clean water services, and to ensure access to appropriate and affordable services, devices and other assistance for disability-related needs" (United Nations, 2006, p. 17). Therefore, States must ensure that essential basic services are available and accessible to persons with disabilities on an equal basis with others. For example, persons with disabilities must be provided with access to running water and hand washing facilities, especially in informal settings.

In the monitoring of Goal 6 of the 2030 Agenda, on ensuring the availability and sustainable management of water and sanitation for all, it has been said that "the COVID-19 pandemic has demonstrated the critical importance of sanitation, hygiene and adequate access to clean water for preventing and containing diseases" (United Nations, 2020f). In addition, "availability and access to water, sanitation and hygiene (WASH) services is fundamental to fighting the virus and preserving the health and well-being of millions".

Household overcrowding is the final variable in the triad of sociodemographic factors that increase the likelihood of coronavirus infection and spread. ${ }^{4}$ This is because the greater the overcrowding, the greater the difficulty in complying with recommended measures, such as physical distancing and self-isolation. This has become evident as the pandemic has spread in the region, as infections have mainly occurred in the larger metropolitan areas, which have sectors with more severe urban deficiencies.

In homes with persons with disabilities, overcrowding is a barrier to implementing measures to prevent COVID-19 infections. It is not easy for persons with disabilities to maintain physical distancing, as they have varying degrees of dependency and therefore need people to support them. In addition, if they are living in poverty, they may have to share rooms with several other members of the household. This can lead to an increased likelihood of infection, because if any member of the household is a carrier of the virus

4 A dwelling is considered to be overcrowded when it is inhabited by an average of 2.5 or more persons per bedroom. 
and cannot physically isolate within the dwelling, the likelihood of the entire household becoming infected is higher.

Figure 7 shows the overcrowding in households with and without persons with disabilities. As shown, there is a higher percentage of overcrowding in households with persons with disabilities. In Guatemala, half of households with persons with disabilities are overcrowded (51\%); in Peru, this percentage is $21 \%$, and in Colombia it is $16 \%$. While overcrowding is greater in rural areas, the proportion of households with persons with disabilities that are overcrowded in urban areas is high, especially in the context of the current health crisis.

Figure 7

Colombia, Guatemala and Peru: proportion of overcrowded households by disability status and area of residence, 2010 census round

(Percentages)

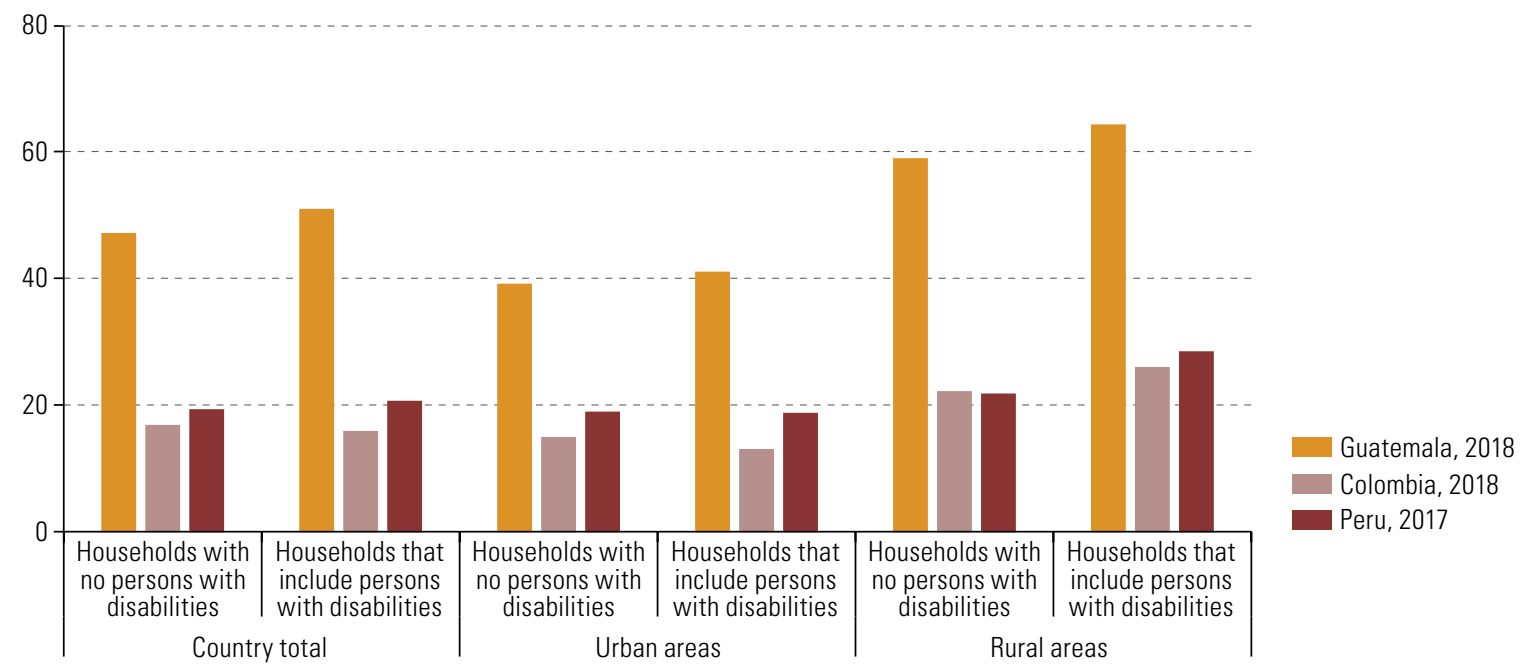

Source: Economic Commission for Latin America and the Caribbean (ECLAC), on the basis of census microdata from the respective countries processed with REDATAM.

It is important for health agencies and those responsible for measures to stop the spread of COVID-19 in the countries of the region to consider the overcrowding that persons with disabilities experience on a daily basis, since this problem is not merely an issue of more than 2.5 people per bedroom. In lockdowns and mandatory confinement, people who live in overcrowded homes spend the whole day gathered in a small space, with no room for privacy and no defined working hours for caregivers or those who support persons with disabilities, or moments for rest. One situation linked to overcrowding that has been highlighted by the current circumstances is the increased exposure of women with disabilities to domestic violence, abuse and mistreatment of all kinds, and an excess burden of care within the home (United Nations, 2020b). Box 2 refers to this issue and identifies some measures that States should implement to alleviate this complex situation.

Another repercussion of overcrowding in households, particularly those with persons with disabilities, is difficulty taking action if a person contracts COVID-19, since it is not easy to establish safe spaces for those living in the household and it is exceedingly difficult to minimize interaction with the other members or with persons providing support or assistance. Therefore, it is urgent that States take measures to support persons with disabilities if they become infected and have to stay at home for the duration of the disease, as hospitalization options generally do not address the needs of persons with disabilities, such as support or assistance. 
Box 2

Persons with disabilities subjected to violence during the COVID-19 pandemic: the right to protection and to live in environments free from violence

There is evidence that persons with disabilities are at greater risk of violence, particularly when they are confined to their homes or long-term facilities. Overall, women and girls with disabilities experience more episodes of sexual, domestic and gender violence, including violence from their partners. The level of violence against girls and women with disabilities is higher than that against those without disabilities, or against men with disabilities.

In the absence of data on disability and gender-based violence in the context of COVID-19, information obtained in similar earlier circumstances has been considered, in which persons with disabilities were particularly at risk. During the ongoing pandemic, an increase has been noted in domestic violence against girls and women; it therefore follows that this is also happening to women and girls with disabilities

It is very difficult for persons with disabilities to report violence, as there are barriers to accessing domestic violence services and assistance. In many cases, they are not included in such services; in other cases, technical support that is accessible for all is not available. For example, telephone hotlines in several countries do not provide interpretation services for the deaf or blind, and shelters and emergency services are ill-equipped to meet the needs of persons with disabilities.

Despite the efforts made in several countries and the issuance of guidelines requiring the services responsible to contact persons with disabilities by telephone during this crisis and to communicate with them in person when confinement measures are lifted, much remains to be done in this regard to comply with the relevant articles of the Convention on the Rights of Persons with Disabilities and for States to ensure that persons with disabilities live in a world free from violence and abuse.

The measures that the Office of the United Nations High Commissioner for Human Rights (OHCHR) has recommended States take in this area include:

- Ensuring that reporting mechanisms, hotlines, emergency shelters and other forms of assistance are accessible to and include persons with disabilities.

- Monitoring the situation of persons with disabilities, particularly those living in isolation, by engaging in proactive outreach including through community and voluntary networks.

- Raising awareness and providing training about the risk of violence faced by persons with disabilities, in particular women and girls with disabilities, and promoting support networks including fostering peer support.

Source: Office of the United Nations High Commissioner for Human Rights (OHCHR), "COVID-19 and the rights of persons with disabilities: guidance", Geneva, 2020 [online] https://www.ohchr.org/Documents/Issues/Disability/COVID-19_and_The_Rights_of_Persons_with_ Disabilities.pdf.

\section{Access to electricity in homes}

Access to electricity is one of the indicators with the highest values in the region, although there are still gaps between urban and rural areas. A recent ECLAC study stated that "on average, more than $98 \%$ of households have access to electricity in urban areas, compared with slightly more than 85\% in rural areas" (ECLAC, 2019b, p. 164).

In the context of the pandemic, in the monitoring of Goal 7 of the 2030 Agenda, on ensuring access to affordable, reliable, sustainable and modern energy for all, it is stated that "lack of access to energy may hamper efforts to contain COVID-19 across many parts of the world" (United Nations, 2020f). The report also says that "energy services are key to preventing disease and fighting pandemics". Lack of access to electricity for communities and households could worsen the health crisis and significantly slow the global recovery.

Having access to energy is important during the COVID-19 emergency. For persons with disabilities this is vital, since in many cases they need assistive devices that require electricity. Therefore, they must have electrical power during this health emergency.

Figure 8 shows that there are almost no gaps in access to electricity between persons with and without disabilities in the three countries analysed. The percentage of the population with disabilities that does not have access to this basic service is quite similar to the percentage for the population without disabilities. 
Figure 8

Colombia, Guatemala and Peru: proportion of population without access to electricity, based on disability status and area of residence, 2010 census round

(Percentages)

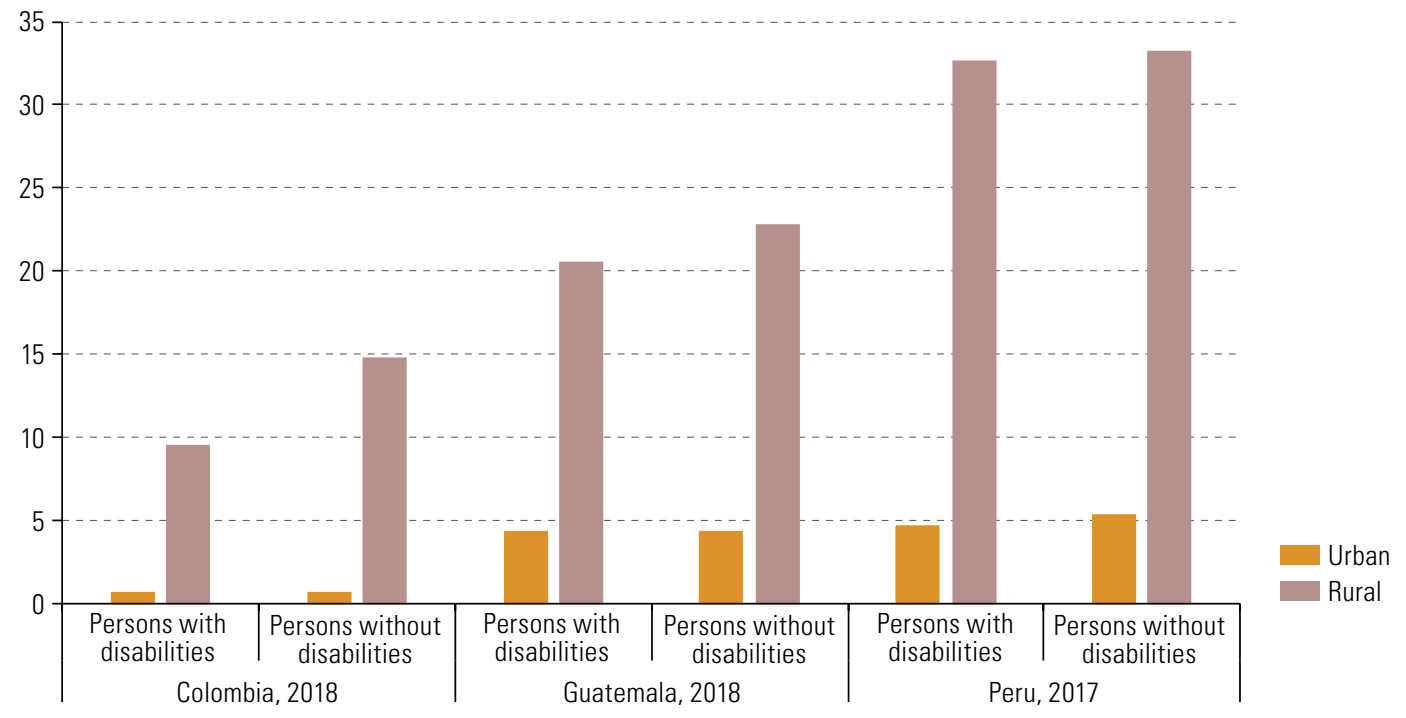

Source: Economic Commission for Latin America and the Caribbean (ECLAC), on the basis of census microdata from the respective countries processed with REDATAM.

WHO and national agencies supporting persons with disabilities have issued recommendations that include some measures to consider if persons with disabilities contract COVID-19. One relates to the importance of their having different safe communication channels with their support networks, via mobile phone, landlines, WhatsApp, social networks, or email, so that friends and family can help when needed. However, all these forms of remote communication depend on access to electricity (WHO, 2020b).

Likewise, some people with multiple or more severe disabilities who are dependent on electrical equipment need power to use assistive devices, so in these circumstances they must be guaranteed access to this service during and after the health emergency.

The Convention on the Rights of Persons with Disabilities, Goal 7 of the 2030 Agenda and priority action 77 of the Montevideo Consensus on Population and Development all promote the development and well-being of people in all territories without any form of discrimination, and the provision of full access to basic social services. States must therefore ensure that these rights are given effect during the health emergency and once it has passed.

\section{Spatial distribution of disability and access to basic services in cities}

Territory is a physical and social space that reflects sociodemographic inequalities and socioeconomic residential segregation (González, 2017). These phenomena have gained ground during the current health, social and economic crisis as infection and mortality rates owing to COVID-19, along with their socioeconomic implications, have hit some territories harder than others.

ECLAC has stated that in this part of the world, "place does matter", as being born in a given territory or residing there has a major impact on the distribution of opportunities for well-being (ECLAC, 2010). Several sections of this document have noted the asymmetries between urban and rural areas, and that, in general, urban areas provide more basic services, access to information technologies, better transport connectivity and access to health services.
Access to electricity in the homes of persons with disabilities is essential so that they obtain information about the pandemic and access services and public policies that benefit them. 
The health crisis caused by COVID-19 has had a severe impact on urban areas. However, although efforts should be made to control the spread of infection in urban centres, this should not lead to the neglect of rural areas, where health and social conditions are worse and the spread of COVID-19 could be devastating (ECLAC/PAHO, 2020).

In the highly urbanized Latin American and Caribbean region, metropolises have been the most affected. Cities such as Sao Paulo, Rio de Janeiro, Lima, Santiago, Mexico City and Buenos Aires lead within their countries in numbers of infections and deaths from COVID-19.

The high population density in cities and metropolises, severe accumulated deficits in sanitation and access to drinking water and overcrowding all contribute to the spread of the pandemic. This is accentuated by the difficulty of complying with stay-at-home orders when some people are forced to go out to work to ensure their daily subsistence in an economic crisis, and because in such densely populated cities it is difficult to comply with physical distancing measures in transport and public spaces.

These deficits and the difficulties of implementing lockdown measures are not evenly distributed across cities, but instead are mainly concentrated in the poorest areas and have the biggest impact on the most disadvantaged socioeconomic groups.

Population census data allow the analysis of deficits in access to basic services and overcrowding in the cities and their components, since the information can be disaggregated based on smaller territorial areas. Maps 1, 2 and 3 show the distribution of the population with disabilities, access to drinking water and overcrowded homes with persons with disabilities in smaller administrative divisions in three cities in the region for which recent information is available: Bogotá, Guatemala City and Lima.

Map 1 shows that, in Bogotá, the highest percentages of persons with disabilities in the metropolitan area are found in the municipalities of Sopó (5.3\%), Sibaté (3.9\%), Bogotá (3.4\%) and Cota (3.1\%). The highest percentages of overcrowding among households with persons with disabilities are observed in the municipalities of Cota (15.4\%) and Sibaté (13.1\%). Some of the municipalities with the highest percentage of households without access to drinking water within the home are Soacha (10.5\%), Cota (6.8\%) and Sopo (6.8\%). Cota and Sopo are also among the municipalities with higher percentages of persons with disabilities, so could record a greater number of infections and should see a redoubling of care measures for these persons.

In Guatemala City, the municipalities with the highest percentage of persons with disabilities are Guatemala and San Pedro Sacatepéquez (3.7\%), San José Pinula (3.3\%), Mixco and Chinautla (3.1\%), and those with the highest proportion of overcrowded households with persons with disabilities are San Pedro Sacatepéquez (54.5\%), San Juan Sacatepéquez (46.1\%), Villa Canales (41.1\%) and Chinautla (40.5\%) (see map 2). Meanwhile, the highest percentages of households without access to drinking water were recorded in the municipalities of San Juan Sacatepéquez (33.4\%), San Pedro Sacatepéquez (21.2\%), Villa Canales (14.6\%) and San José Pinula (12.2\%). The largest proportion of persons with disabilities and the most serious deficits are evident in San Pedro Sacatepéquez and San José Pinula, where the levels of poverty and social vulnerability are high.

Lima has been one of the cities hit hardest by the pandemic, and 17 of the 53 municipalities that make up this metropolitan area are among those with the highest percentages of persons with disabilities (from $11.6 \%$ to 13.3\%) (see map 3). The districts with the highest proportion of overcrowded households and persons with disabilities include Santa Eulalia and Pachacamac, where the percentage varies from $21 \%$ to $26 \%$. Seventeen districts of the metropolitan area reflect the highest proportion of households without access to drinking water within the home, with percentages ranging from $40 \%$ to $74 \%$ More than half of the households in Punta Negra, Punta Hermosa and Cienaguilla are without access to drinking water within the home. These indicators show that there are areas of Lima where urban deficits may contribute to the spread of the virus and the emergence of a greater number of COVID-19 cases. 


\section{Map 1}

Bogotá: proportion of persons with disabilities, of overcrowded households with persons with disabilities, and of households without access to drinking water, by municipality, 2018 census

(Percentages)
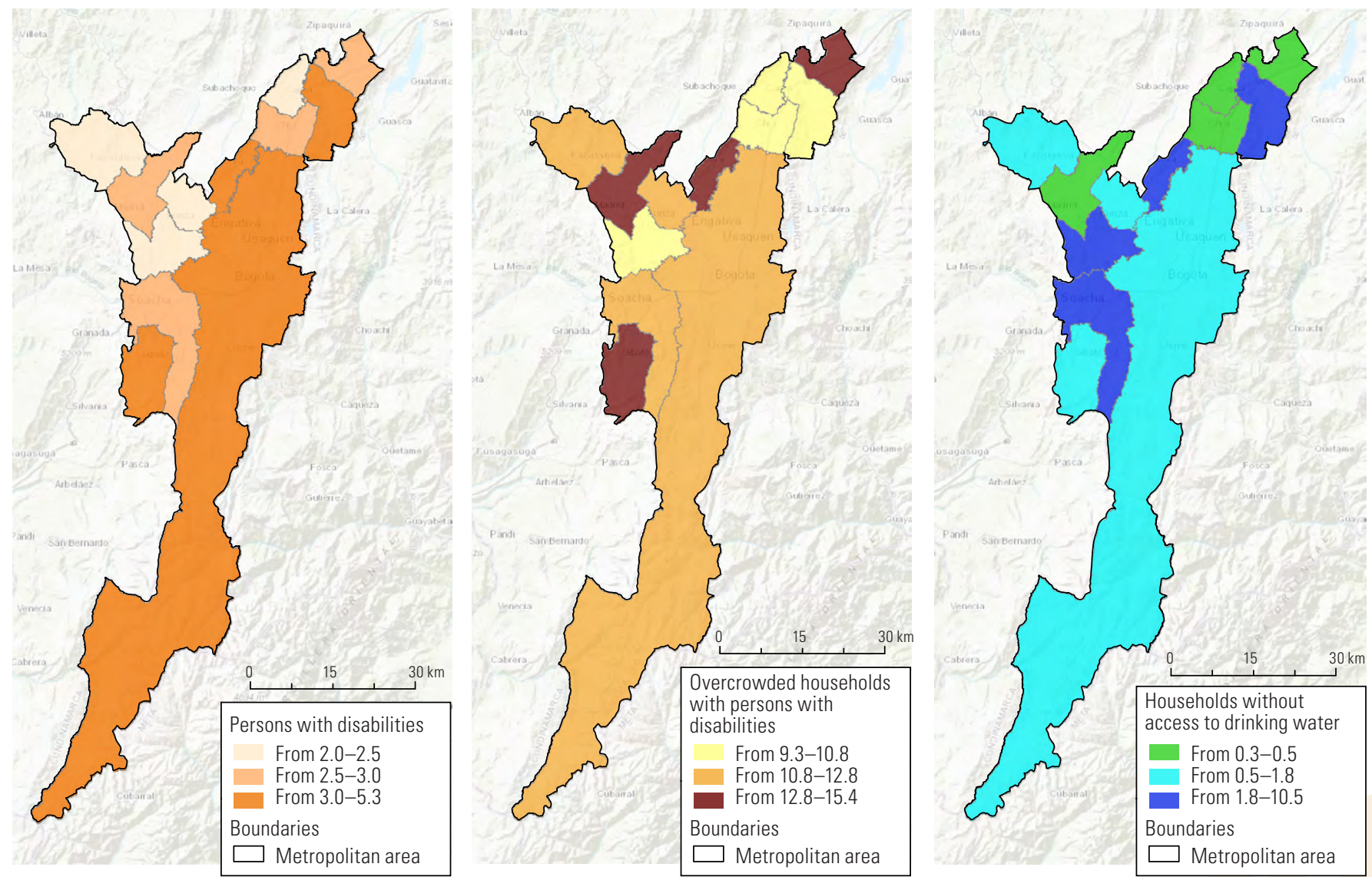

Source: Economic Commission for Latin America and the Caribbean (ECLAC), on the basis of census microdata from Colombia processed with REDATAM; Latin American and Caribbean Demographic Centre (CELADE)-Population Division of ECLAC, Spatial Distribution and Urbanization in Latin America and the Caribbean (DEPUALC), 2020 [online] https://celade.cepal.org/bdcelade/depualc/. 


\section{Map 2}

Guatemala City: proportion of persons with disabilities, of overcrowded households with persons with disabilities, and of households without access to drinking water, by municipality, 2018 census

(Percentages)

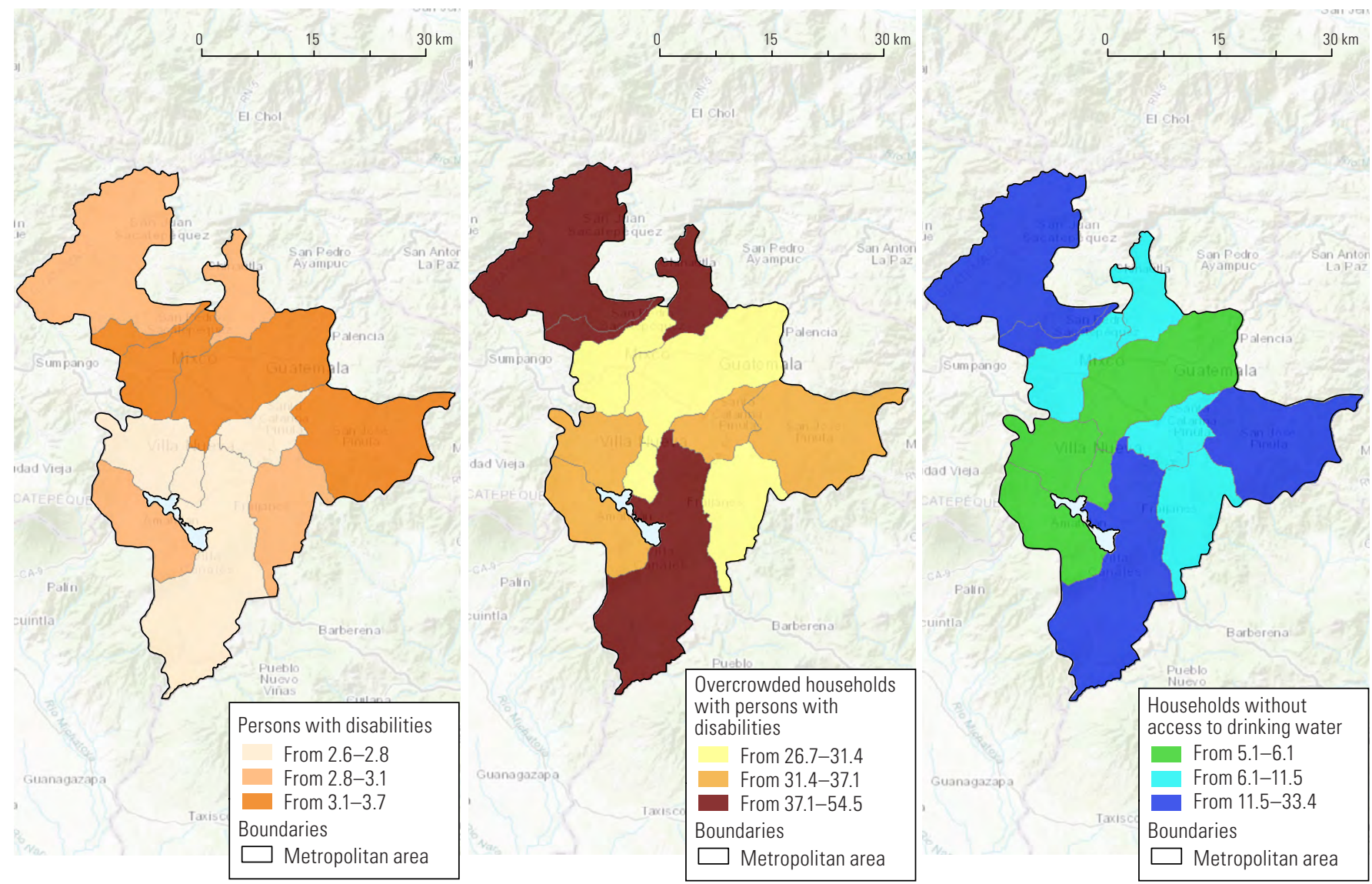

Source: Economic Commission for Latin America and the Caribbean (ECLAC), on the basis of census microdata from Guatemala processed with REDATAM; Latin American and Caribbean Demographic Centre (CELADE)-Population Division of ECLAC, Spatial Distribution and Urbanization in Latin America and the Caribbean (DEPUALC), 2020 [online] https://celade.cepal.org/bdcelade/depualc/. 


\section{Map 3}

Lima: proportion of persons with disabilities, of overcrowded households with persons with disabilities, and of households without access to drinking water, by district, 2017 census

(Percentages)
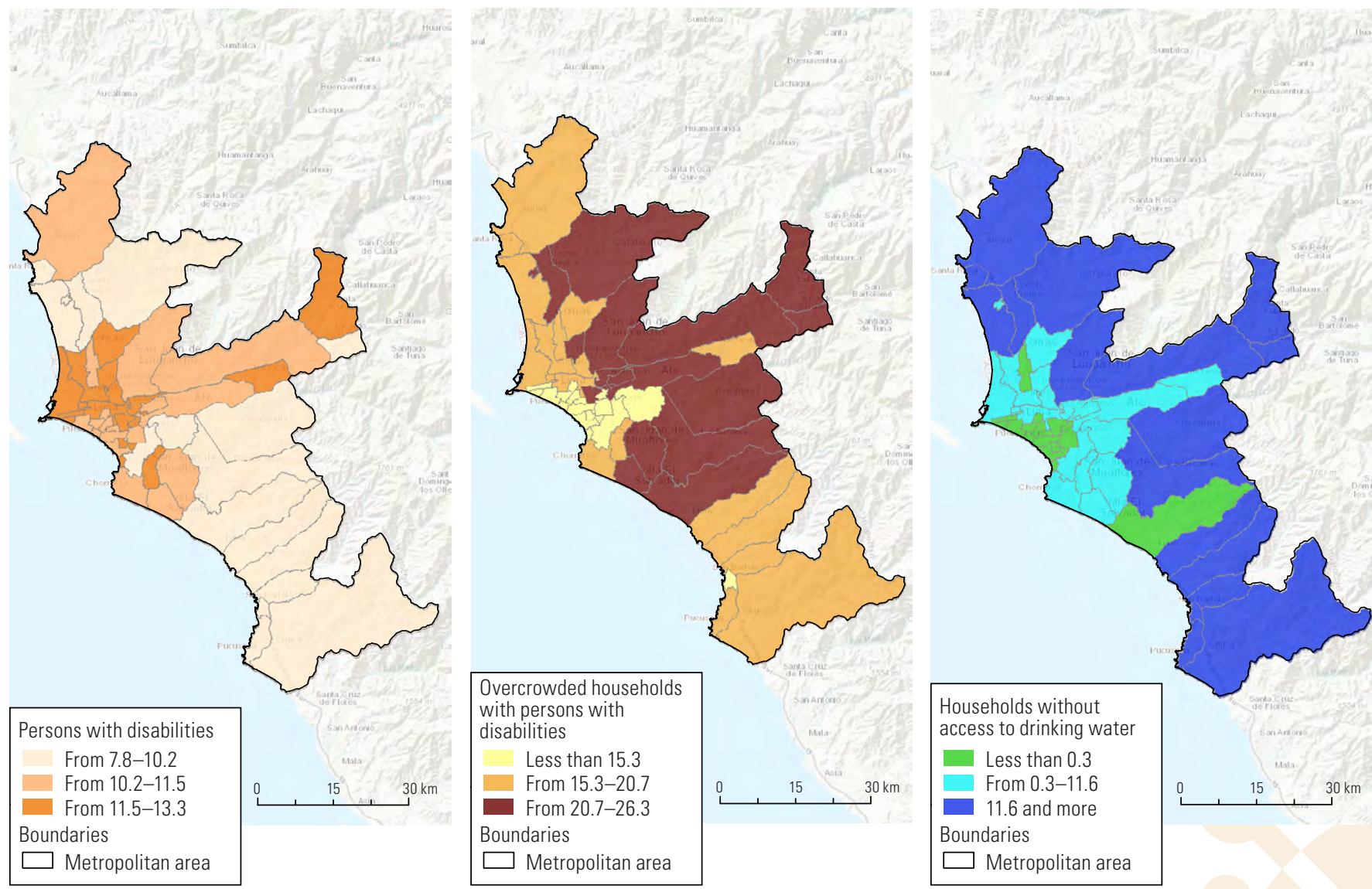

Source: Economic Commission for Latin America and the Caribbean (ECLAC), on the basis of census microdata processed with REDATAM; Latin American and Caribbean Demographic Centre (CELADE)-Population Division of ECLAC, Spatial Distribution and Urbanization in Latin America and the Caribbean (DEPUALC), 2020 [online] https://celade.cepal.org/bdcelade/depualc/. 
Territory matters: the impact of the pandemic on different areas of cities has varied.
The three cases described above confirm that the pandemic has exposed deep inequalities in how people in cities live, particularly persons with disabilities. The crisis has had the biggest impact on those who were already vulnerable (UN-HABITAT, 2020).

This analysis also reveals the importance of local governments and their coordination of crisis management in cities, both in terms of implementing measures during the pandemic and in planning medium- and long-term actions. A joint statement by the Special Envoy of the Secretary-General on Disability and Accessibility and the Coordinator of the Cities4All Network on Local governments and persons with disabilities in relation to COVID-19 calls for greater leadership from local and regional governments, as they are in direct contact with the population in their respective jurisdictions, and are keenly aware of the demands and needs of the population to be met during the COVID-19 emergency. They are also called upon to interact with central governments for the well-being of the population (United Nations, 2020a). In this respect, the statement emphasizes that this crisis is an opportunity to "effectively consolidate the universal accessibility of cities and human settlements, as an effective way to fulfil human rights and overcome poverty, counting for this with the Human Rights model recognized in the United Nations Convention on the Rights of Persons with Disabilities, the 2030 Agenda on Sustainable Development, the New Urban Agenda, the Sendai Framework for Disaster Risk Reduction and the Strategy of the WHO Global Network of Age-Friendly Cities and Communities, always taking into account the reality of each local context and the needs and proposals of citizens" (United Nations, 2020a, p. 3-4). This implies major challenges in the medium and long term, which involve rethinking cities and metropolises in the light of Goal 11 of the 2030 Agenda, which aims to make cities and human settlements inclusive, safe, resilient and sustainable, with accessible transport, green areas and public spaces, so as to leave no one behind. This in turn relates to the Montevideo Consensus on Population and Development, particularly several priority actions in chapter $\mathrm{G}$, which deals with territorial inequality, spatial mobility and vulnerability. It highlights the importance of the design and execution of territorial management plans, policies and programmes, and instruments at different subnational, urban and city-system levels, based on rights, environmental sustainability, the gender perspective and interculturalism.

\section{Education attainment and attendance}

Children, adolescents and young people with disabilities and of school age face various accessibility barriers. There are physical barriers related to access to schools and transport, but also others involving finances and the school context (learning materials, teacher training and adapted curricula). They also face attitudinal barriers from teachers, classmates, schoolmates, and parents of other students on a daily basis (ECLAC, 2019d).

Using information from censuses conducted in the early 2010s, González and Stang (2014) found that the percentage of school attendance of children in the 3-4 and 5-11 age groups with and without disabilities was quite similar. Indeed, they noted that there were virtually no gaps between children with and without disabilities, and that trends among adolescents and young people were similar (González and Stang, 2014).

This indicates that when the disability is not among the most severe, inclusive education programmes allow children with disabilities to pursue their studies, either in specialized centres or in mixed education institutions. Even so, children, adolescents and young people with disabilities receiving a formal education generally do so in "special" schools, and the proportion that can participate in inclusive schooling processes varies among and even within countries, which means that these persons do not participate in inclusive schooling. In addition, many of them lag behind in school and are sometimes kept in formal education beyond the average age of graduation.

The most recent census data from the three countries analysed show a similar situation regarding access to formal education for persons with disabilities. Although a lower percentage of persons with disabilities have access than persons without disabilities in the three countries, the gaps do not exceed 17, 14 and 5 percentage points in Guatemala, Colombia and Peru, respectively (see figure 9). In addition, the access of men with disabilities to training is very similar to that of women in the same situation. When 
comparing rural and urban areas, however, inequalities in access are evident: a very low proportion of children and adolescents with disabilities attend school in rural areas. One of the lowest percentages of school attendance is observed in the rural areas of Peru, where only $9 \%$ of children with disabilities attend school. In urban areas of the country, however, school attendance by children with disabilities is 91\%. In Colombia, the gap between urban and rural areas is smaller, but this rural-urban asymmetry is also clear: one in four children with disabilities attends school in rural areas, while three in four do so in urban areas. Although the gap is even smaller in Guatemala, the trend is the same: $40 \%$ of children with disabilities in rural areas attend school, while in urban areas the proportion is as high as $60 \%$.

Figure 9

Colombia, Guatemala and Peru: proportion of children and adolescents attending school, by disability, sex and area of residence, 2010 census round

(Percentages)

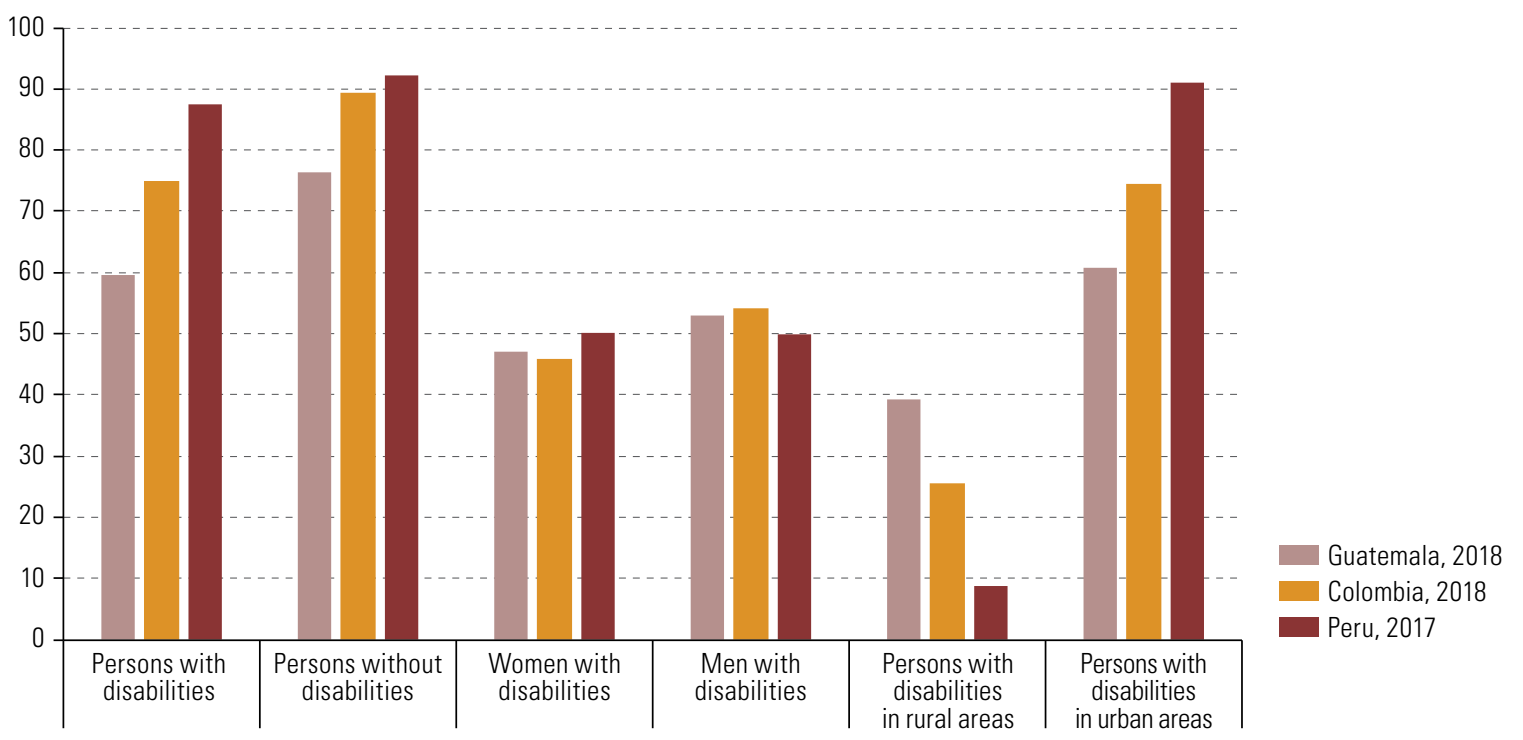

Source: Economic Commission for Latin America and the Caribbean (ECLAC), on the basis of census microdata from the respective countries processed with REDATAM.

When COVID-19 arrived in the region, one of the first measures taken in most countries was the suspension of face-to-face classes at all levels. Thus, distance learning modalities were deployed fairly rapidly, through a variety of formats and platforms (ECLAC/UNESCO, 2020). School closures have also meant the interruption of the provision of food and nutrition services to the student population, particularly in the most vulnerable sectors, which have also been the most affected during the pandemic. Schools provide other services that are highly supportive of students, services to which students have not had access during closure, for example, the provision of contraceptives, mental health services and support for inclusive learning, or the organization of recreational activities (ECLAC/UNESCO, 2020).

While school closures have affected all students in general, the impact on those with disabilities and their families has been especially complicated. The interruption of classroom activities is expected to have a significant effect on the learning of students with disabilities, as this means they do not have the support of the multidisciplinary teams that normally guide their school activities. In addition, work routines are essential for good education results, and these are not easy to implement at home (ECLAC/UNESCO, 2020).

While every effort has been made to implement learning activities through virtual modalities, whether synchronous or asynchronous, for students with disabilities this has been a double challenge, since teaching platforms must be adapted to their type of disability (visual, auditory or physical, among others), and this has not been achieved in all cases. Moreover, as will be 
Lagging education attainment and lower school attendance of students with disabilities may be accentuated in humanitarian crises if specific measures are not implemented for them. shown in the next section, there are gaps in access to computers and the Internet in households with persons with disabilities. Therefore, although plans have been made to promote the use of digital devices in education systems, students with disabilities have found it much more difficult to access them (ECLAC, 2020a; ECLAC/UNESCO, 2020; Ullmann and others, 2018).

Given the barriers that students with disabilities may face in accessing virtual education, there may be a risk of disengaging from education and dropping out of school, particularly among students belonging to the groups most vulnerable during the pandemic and the consequent health, social and economic crisis (ECLAC/UNESCO, 2020).

Short- and medium-term measures should be implemented to avoid permanent disruption of school attendance. A recent ECLAC/UNESCO report (2020) included recommendations to ensure that the most susceptible children and adolescents do not disengage from education and to exhaust all possible options to encourage them to continue learning. This is even more important for students with disabilities, and the barriers they may encounter should be reduced as much as possible, with efforts focused on assessing on a case-by-case basis the need for support to continue studies and make the necessary adaptations. It is crucial that these students do not lose the link to their formal educational settings, so that they are not excluded because of the absence of technical support and reasonable accommodation. In the medium term, mechanisms should be created to ensure that there is no negative impact on the education experience or advancement of students who have not been able to continue learning during this period. This implies coordinating measures such as the elimination of repetition and establishing flexible mechanisms for curricular continuity along with support strategies for the recovery and acceleration of learning (ECLAC/UNESCO, 2020, p. 14). For students with disabilities, these measures are necessary to continue learning, considering that the education process must be adapted to their needs and carried out at a pace to which they can adapt. However, another challenge is also expected to arise in the medium and long term: ensuring that students with disabilities are not left at home and limited only to distance learning, for the sake of simplifying accessibility. The greatest asset of inclusive education settings are the relationships built among all the students, and the ties between them, their teachers and the education community, which not only improve the condition of students with disabilities, but also enrich the relationships among everyone.

The measures and actions implemented in the short and medium term must consider the protection and guarantee of children's rights, including the rights of children with disabilities and the social protection of families with children with disabilities. In that regard, article 24 of the Convention on the Rights of Persons with Disabilities, which refers to education, says that "States Parties shall ensure an inclusive education system at all levels and lifelong learning", and that one of the reasons for doing so is "enabling persons with disabilities to participate effectively in a free society" (United Nations, 2006, p. 14). Therefore, in realizing this right under the Convention, States Parties shall ensure that disability is not a reason for exclusion from the general education system, or for the exclusion of children from free and compulsory primary education or from secondary education. They shall also ensure that reasonable accommodation is provided according to individual needs, and that, within the general education system, persons with disabilities are provided with the necessary support to facilitate their effective training. States Parties shall facilitate the adoption of effective individualized support measures in environments that maximize academic and social development, consistent with the goal of full inclusion (United Nations, 2006, p. 14). In addition, Goal 4 of the 2030 Agenda, to ensure inclusive and equitable quality education and promote lifelong learning opportunities for all, sets out a number of targets that consider persons with disabilities and emphasize access to inclusive physical school spaces and the development of education curricula for all. One concern in this regard is that students with disabilities should not be left behind or out of education systems because of this global pandemic, as this could jeopardize hard-won gains in inclusive and comprehensive education.

\section{Access to and use of information and communications technologies (ICT)}

During the health crisis caused by COVID-19, a recommendation was put forward to "make information and communications technologies (ICTs) and assistive technologies that promote communication and autonomy of individuals in emergency situations available 
to public services and persons with disabilities — such as video chats for the use of interpreters in health services, cellular applications to detect infections, location indicators, emergency hotlines, phone numbers to get basic supplies delivered, programmes to describe environments to blind people, read labels, and so on-" (OAS, 2020, p. 31). The aim is to narrow the gaps in digital access to information about and during the pandemic since, in instances of physical distancing and confinement in the home, access to information and communications technologies (ICTs) has become even more important, especially since these technologies can be a key tool to limit the negative impact on persons with disabilities and their families (ECLAC, 2020a)

At the beginning of the 2010s, census data already showed that access to ICTs was a proxy indicator of poverty and inequality. This was because such access was more limited in rural areas than in urban areas and among the poorest groups, older persons and persons with disabilities compared to the general population (ECLAC, 2012). AWHO study indicated that persons with disabilities have significantly lower rates of ICT use than persons without disabilities, and that, in some cases, persons with disabilities may be unable to access even basic products and services such as telephones, television and the Internet $\mathrm{WHO}$, 2011, p. 10). This situation has not changed much in the present decade and the gaps have rather widened in this emergency situation: hence the importance of strengthening access to technologies, especially from a financial point of view (ECLAC, 2020a).

In the three countries with the most recent census data, there is a gap between persons with and without disabilities with regard to ICTs. Figure 10 shows the percentage of people without access to the Internet at home, based on disability status and area of residence. Guatemala stands out, as it reflects the highest percentages of the population without access, both among persons with disabilities and persons without disabilities. In Peru, $70 \%$ of the population does not have access to the Internet at home, and in Colombia the figure is lower (50\%). In all three countries, persons without disabilities have greater access to the Internet, although this gap is much more evident in Colombia. Despite the fact that the beginning of the 2020s is very close, there is still a gap between urban and rural areas in terms of Internet access: the percentage of people with access to the Internet in rural areas is very low in all three countries. In urban areas, the percentage of the population without access is decreasing, although it is still higher among persons with disabilities.

Figure 10

Colombia, Guatemala and Peru: proportion of population without access to Internet at home, based on disability status and area of residence, 2010 census round

(Percentages)

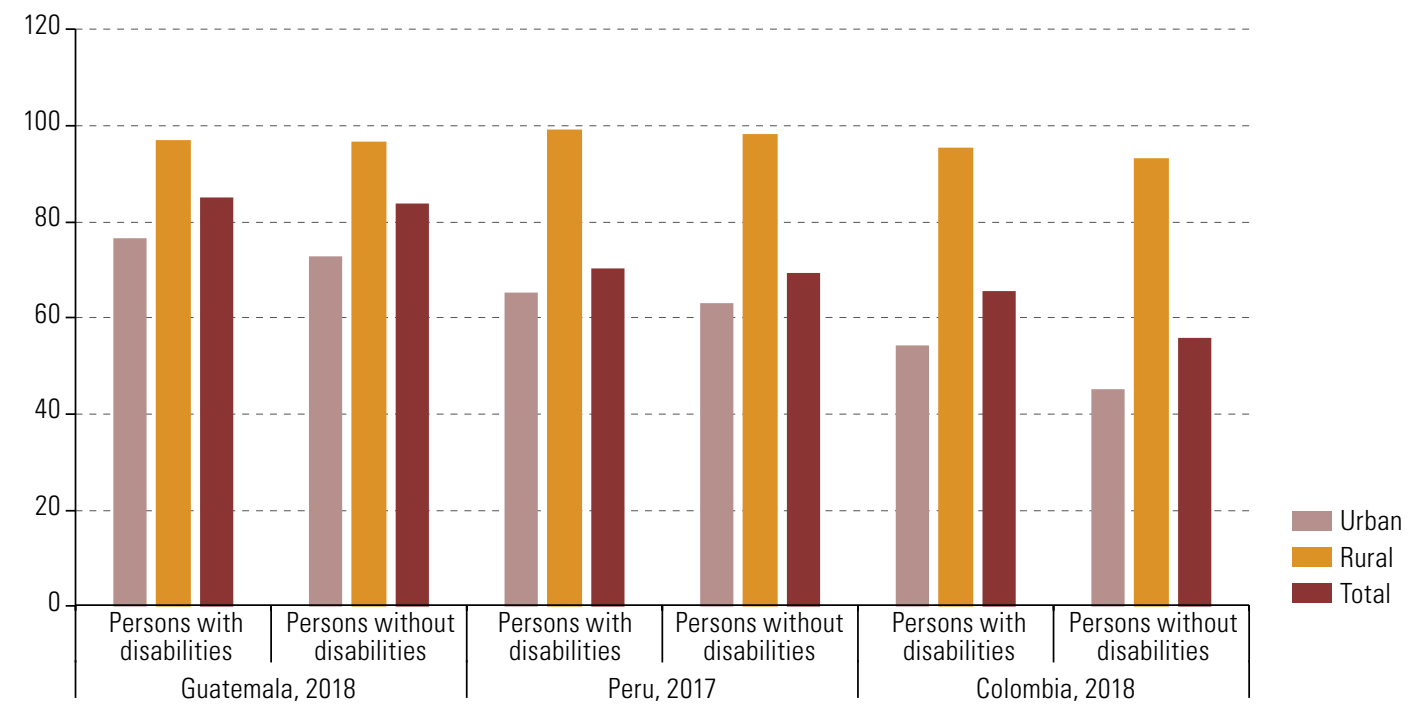

Source: Economic Commission for Latin America and the Caribbean (ECLAC), on the basis of census microdata from the respective countries processed with REDATAM. 
The percentage of the population without access to a computer is relatively lower, although it remains high: in Guatemala, it is 79\% and in Peru, 63\% (see figure 11). There are welldefined gaps between urban and rural areas, especially in Peru. In addition, the percentage of persons with disabilities who do not have access to a computer is higher than that of persons without disabilities: in Guatemala, the figure is $82 \%$ and in Peru, $65 \%$. The percentage is over $94 \%$ in the rural areas of both countries, dropping to $73.3 \%$ and $59 \%$ in the urban areas of Guatemala and Peru, respectively. These data show that most persons with disabilities do not have access to a computer at home. Although in other countries of the region the penetration of computers in the home is higher, the gaps between persons with and without disabilities, and between urban and rural areas, remain.

Figure 11

Guatemala and Peru: proportion of population without access to a computer at home, based on disability status and area of residence, 2010 census round

(Percentages)

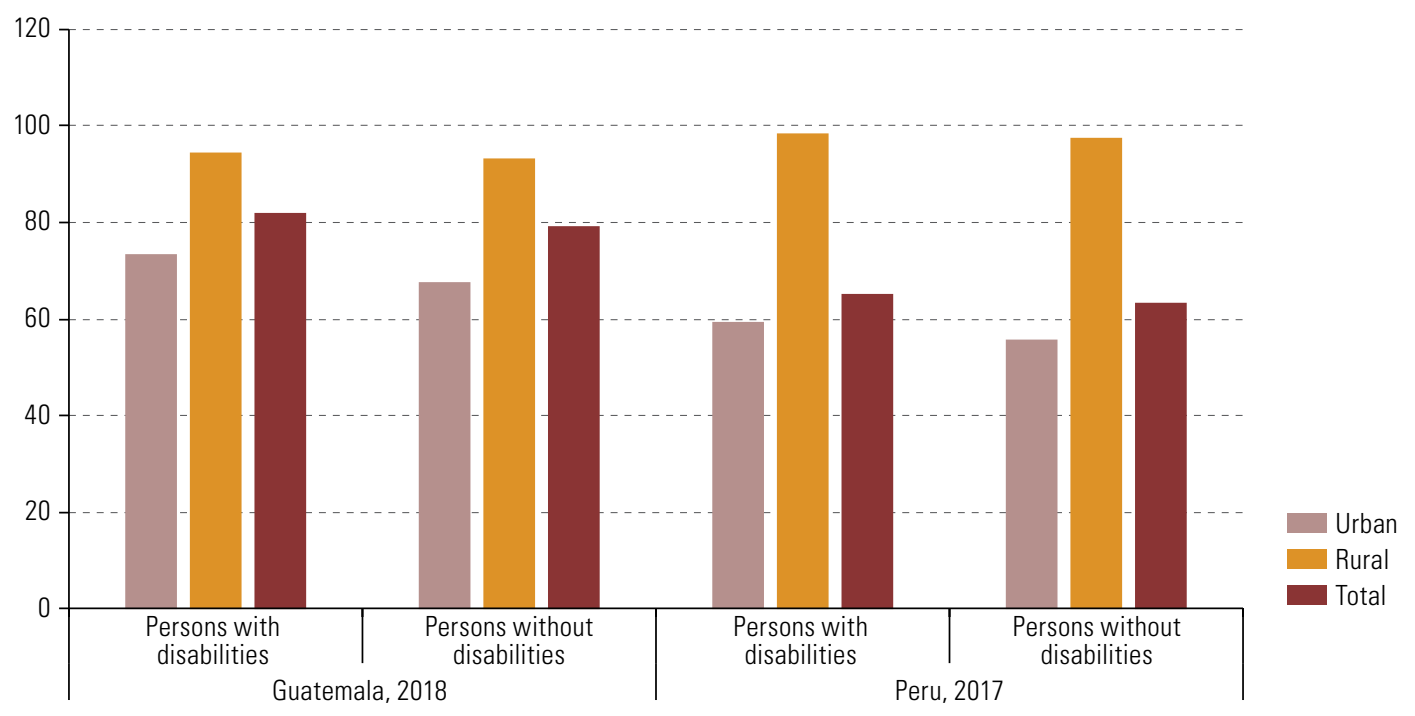

Source: Economic Commission for Latin America and the Caribbean (ECLAC), on the basis of census microdata from the respective countries processed with REDATAM.

The penetration of mobile phones is higher in households in both Guatemala and Peru. About 37\% of the Guatemalan population does not have access to a mobile phone, and this percentage increases to $56 \%$ for persons with disabilities (see figure 12). In Peru, the percentage drops to $15 \%$ of the total population and to $18 \%$ among persons with disabilities. In general, a higher percentage of the population in rural areas does not have access to mobile phones, a trend that can be seen in most of the region's countries.

These asymmetries in access to ICTs clearly show that the possession of these technologies predominates in urban areas and, indeed, is more concentrated among persons without disabilities

In the context of a pandemic and confinement it is very important to expand access to ICTs, particularly in rural areas and among persons with disabilities. However, the fact that persons with disabilities face specific barriers with respect to the use of ICTs, depending on the type of disability, should also be taken into consideration. This means that the percentages of access described do not show the actual extent to which people with disabilities use these technologies. 
Figure 12

Guatemala and Peru: proportion of population without access to a mobile phone at home, based on disability status and area of residence, 2010 census round

(Percentages)

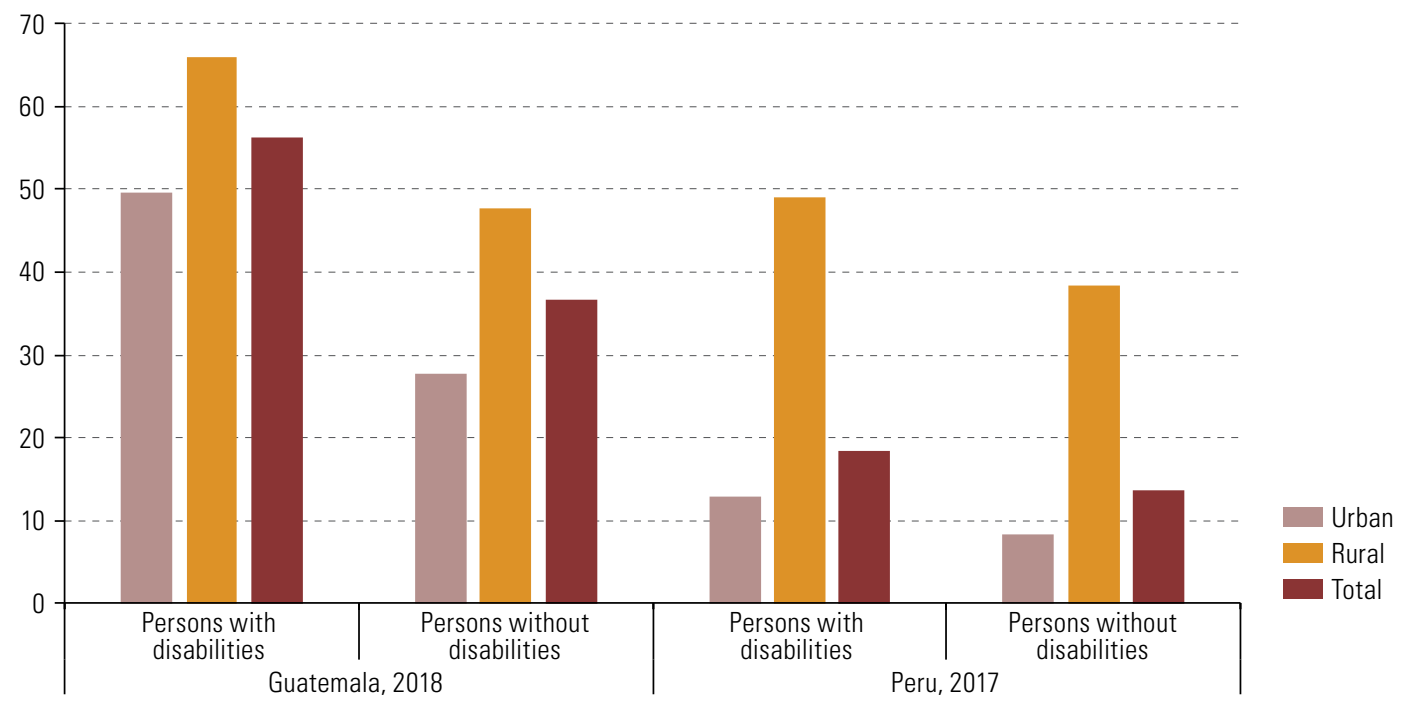

Source: Economic Commission for Latin America and the Caribbean (ECLAC), on the basis of census microdata from the respective countries processed with REDATAM.

According to some research on this issue, persons who are blind or visually impaired face barriers when using visual services, mainly in terms of the content and indications that appear on computer, mobile phone or tablet screens. In these cases, therefore, it is necessary to use a non-conventional interface, as conventional ones are a major impediment to Internet access. For persons who are deaf or hearing impaired, the main barriers relate to the use of content and the provision of voice-based services, as well as the ability to communicate with others through voice telecommunications. For persons with physical disabilities or reduced mobility, although the barriers they encounter differ according to the degree of severity of their disability, these barriers are often related to the use of interfaces requiring precise manipulation, such as a computer mouse and keyboard, telephone buttons or the screens of touchscreen phones. Therefore, it is not enough to support access to ICTs only in economic terms, but applications should be created that allow for inclusive access to ICTs, taking into account different types of disability. This would enable persons with disabilities to use ICTs in their homes

In countries where there is low ICT penetration in households, especially those of persons with disabilities, it is also useful to consider television and radio as devices that can provide important information during this emergency. Television channels should include sign language and subtitles to make this information inclusive. It is important to bear this in mind, since television and radio penetration is generally high in households across the region.

\section{Labour inclusion}

Before the crisis caused by the COVID-19 pandemic in the region, data indicated that unemployment rates were higher among persons with disabilities, who were more likely to be economically inactive than persons without disabilities. If they were working, they were more likely to have low-paying, informal and unstable jobs with limited career prospects (ECLAC, 2019d).
Access to and use of information and communications technologies (ICTs) provides opportunities to access information and to reduce the negative impact of physical distancing and confinement. 
A recent report Persons with disabilities and coronavirus disease (COVID-19) in Latin America and the Caribbean: status and guidelines, indicates that persons with disabilities in the region had a weak position in the labour market and their participation in that market was mainly concentrated in the service sector and in informal employment. This population is therefore likely to be particularly affected by the adverse labour market scenario during the crisis and the recovery period (ECLAC, 2020a).

This document states that persons with disabilities are more likely to have health problems that increase their risk of contracting COVID-19 and outlines the reasons for this. In addition, the overrepresentation of persons with disabilities among the poor and in the informal economy increases the risk of infection. These risks are higher among women, older persons and indigenous people with disabilities (United Nations, 2020a). The measures taken to prevent the spread of COVID-19 can create new barriers for people with disabilities. The risks must therefore be addressed in a way that protects them from infection, but at the same time allows them to maintain their work and income (ILO, 2020).

Census data from Peru and Guatemala can be used to estimate the percentage of persons with disabilities who work and to determine their occupational categories. The proportion of persons with disabilities who work is small. In fact, less than one third are engaged in a paid activity: 27\% in Guatemala and 31\% in Peru.

Occupational categories can be used as a proxy indicator to analyse the working relationships, authority, economic risk and job insecurity of workers with disabilities. This information is presented in figure 13 , which shows that, regardless of age, persons with disabilities are mainly own-account workers and employees or workers: about $80 \%$ of people with disabilities working in Guatemala and $90 \%$ in Peru fall into these two categories. The proportion of employees and workers is higher among those under 30 years of age, while the proportion of own-account workers increases with age. Between $20 \%$ and $30 \%$ of children under 18 years of age are involved in support activities in family businesses.

Figure 13

Guatemala and Peru: distribution of occupational categories according to the age of workers with disabilities, 2010 census round

(Percentages)

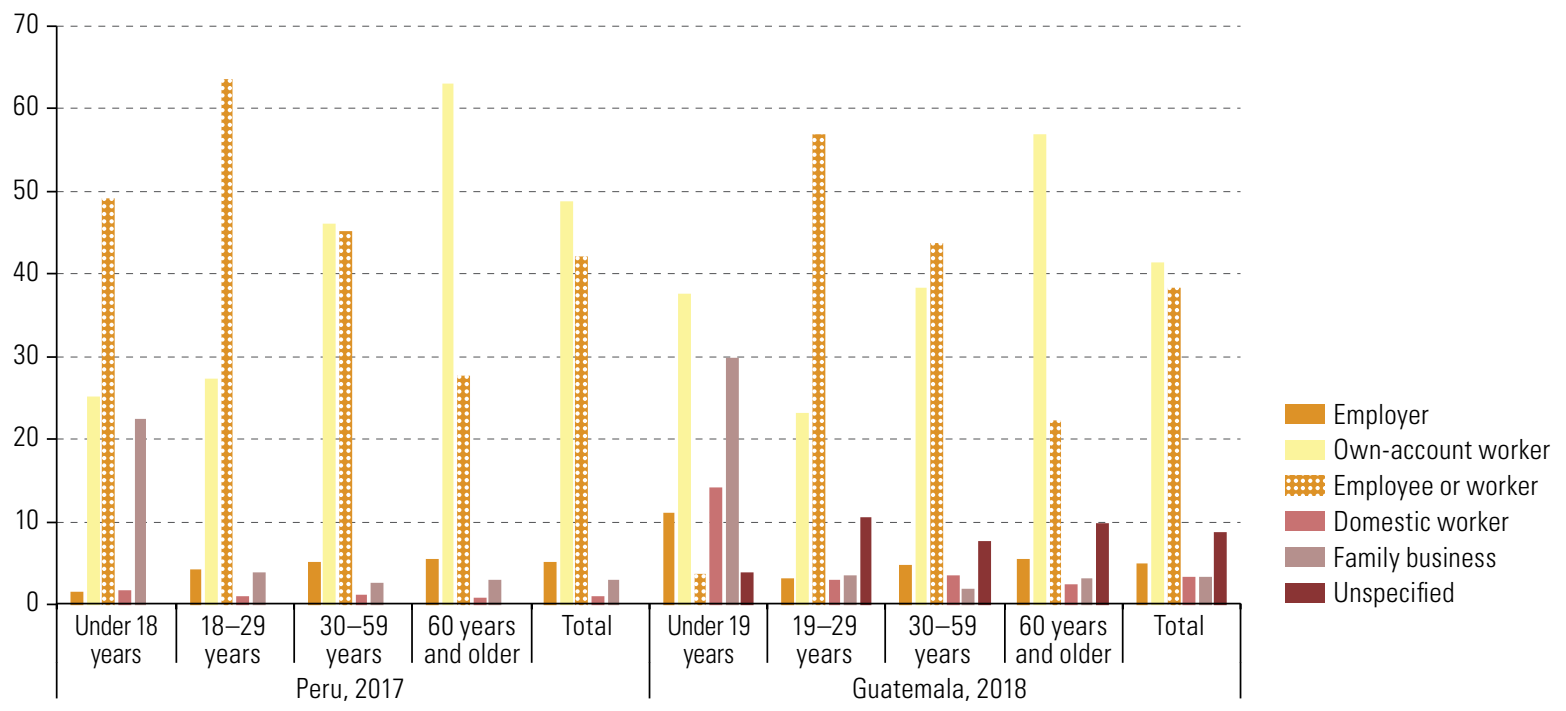

Source: Economic Commission for Latin America and the Caribbean (ECLAC), on the basis of census microdata from the respective countries processed with REDATAM.

There are also differences between urban and rural areas, as there is a higher percentage of persons with disabilities working as employees or workers in urban areas of Peru and Guatemala, while in rural areas they are mostly own-account workers. 
The already high level of job insecurity for persons with disabilities is increasing because of the crisis caused by COVID-19. This stems mainly from the fact that there has been a reduction in working hours, a decline in wages and, indeed, an increase in redundancies in formal employment. In order for persons with disabilities to continue working during the pandemic, employers should make appropriate adjustments in workplaces or offer the possibility of teleworking, as well as ensure that information on the health risks posed by COVID-19 is provided to workers in an accessible manner (ILO, 2020). Thus, it is important to ensure that digital content is accessible and, where necessary, made available in sign language and that meeting formats are also accessible. These guarantees have not been easy to implement and, in many cases, it has been easier to opt for people with disabilities to remain confined to their homes and wait for the pandemic to pass or for a vaccine to be developed to protect them. Therefore, although no figures are available, civil society organizations working with persons with disabilities in the region have reported that unemployment has increased among this group. ${ }^{5}$

Meanwhile, persons with disabilities who are own-account workers or who work in the informal economy are in a particularly difficult situation. Employment has fallen because of physical distancing and bans on movement (ECLAC/ILO, 2020). This has mainly affected jobs which involve a high and medium-high risk of infection: the former include, for example, trade, food services and vehicle repair, and the latter include transport and storage, information and communications, entertainment and recreation, and other services. Workers engaged in these activities must receive support to maintain their livelihoods and take appropriate precautions. Workers with disabilities are in a vulnerable situation in the informal economy, particularly with regard to measures taken to mitigate the spread of the coronavirus (ILO and others, 2020)

Article 27 of the Convention on the Rights of Persons with Disabilities, which addresses work and employment, asserts that "States Parties recognize the right of persons with disabilities to work, on an equal basis with others; this includes the right to the opportunity to gain a living by work freely chosen or accepted in a labour market and work environment that is open, inclusive and accessible to persons with disabilities" (United Nations, 2006, p. 16). States must therefore create the conditions for workers with disabilities to continue carrying out these activities with the greatest possible safeguards. This means developing protocols and various actions that address these issues together with the relevant actors in the world of work, to ensure protection from COVID-19. This could be achieved through the implementation of accessible occupational health and safety measures, the provision of social protection that allows for immediate assistance, consultation with persons with disabilities, meaningful participation of persons with disabilities and the establishment of inclusive financial mechanisms (ILO, 2020).

Now more than ever, the 2030 Agenda and the Sustainable Development Goals (SDGs), particularly Goal 8, to promote sustained, inclusive and sustainable economic growth, full and productive employment, and decent work for all, are gaining momentum. Those principles must be applied so that persons with disabilities are not left behind and are not left without decent work. The aim should be for all women and men, including young people and persons with disabilities, to achieve full and productive employment and decent work. In the current context, it is necessary to monitor compliance with target 8.8 of the above-mentioned Goal, which refers to protecting labour rights and promoting a safe and secure working environment for all workers, including migrant workers and, in particular, migrant women and persons in precarious employment, including persons with disabilities. In order to ensure this monitoring, efforts to obtain updated data and statistics on persons with disabilities and employment must be intensified.

\footnotetext{
Some of the virtual forums that have dealt with the topic are: Economic Commission for Latin America and the Caribbean (ECLAC), "Seminario web: El Impacto Multidimensional de la Crisis por la COVID-19 en las Personas con Discapacidad" [online] https://www.cepal.org/es/eventos/seminario-web-impacto-multidimensionalla-crisis-la-covid-19-personas-discapacidad; Latin American Network of Non-Governmental Organizations of Persons with Disabilities and their Families (RIADIS), "Estadísticas sobre Discapacidad para Políticas Públicas Eficaces y Respuestas Inclusivas durante la Pandemia por el COVID-19" [online] https://www.facebook.com/ RIADISORG/videos/2542436402753004; Ibero-American General Secretariat (SEGIB), "Ciclo de webinars para incluir a las personas con discapacidad en la respuesta a la crisis por el COVID-19" [online] https://www. segib. org/ciclo-de-webinars-para-incluir-a-las-personas-con-discapacidad-en-la-respuesta-a-la-crisis-por-el-covid-19/.
}

Problems relating to the integration of persons with disabilities into the labour market include access, lack of reasonable accommodation, discrimination and the persistence of negative stereotypes, all of which have been accentuated during the health crisis. 


\section{Recommendations on public policy actions}

There has been no homogeneous response in the region to the pandemic: each country has responded in its own time and in different ways. Consequently, infection and mortality rates differ among countries, and several countries lead global statistics in both variables. Currently, there is great uncertainty in the region about how this pandemic will continue to evolve and what the economic consequences will be in the medium and long term. Economies have already been affected, and the population has also suffered various social and psychological effects.

This pandemic has revealed the enormous inequalities that persons with disabilities face in different areas, some of which are presented in this document. One very important aspect is statistical invisibility: if no information is available on persons with disabilities, it is very difficult to implement favourable public policy actions for this population group. This has been made clear in this document, which has underscored that the countries of the region do not always have updated and comparable information, obtained in compliance with international recommendations, that allows for rapid intervention in crisis and disaster situations.

In the various reports that ECLAC has prepared in connection with COVID-19, it is emphasized that "the coronavirus disease (COVID-19) pandemic has severe health effects and serious implications for economic growth and social development" (ECLAC, 2020d, p.1). The pandemic has hit hardest the most vulnerable population groups, including persons with disabilities, who were already socially and economically disadvantaged.

The main actions implemented in some countries of the region to support persons with disabilities in different sectors during the COVID-19 crisis include the following:

- Systems have been designed to ensure that important information is provided in accessible formats, considering the use of sign language interpreters and subtitling, for example.

- Local family health centres have disseminated clear and concise information aimed at people with psychosocial disabilities.

- Civil society organizations have implemented precautionary measures in response to the particular nature of disabilities. For example, they have developed transparent masks for deaf persons and masks with printed messages informing that the person has a disability.

- In some countries of the region where total confinement or strict quarantine has been implemented, a special permit has been created to allow children with autism spectrum disorder to go out into public spaces.

- Formal support persons and caregivers have been exempted from travel and physical distancing restrictions to allow them to assist persons with disabilities.

- Community support networks have been established and volunteers have been recruited to support persons with disabilities and older persons with purchases of food and other items.

- Specific opening hours have been established so that persons with disabilities and their support persons or caregivers can make essential purchases.

- In some countries, recipients of disability benefits will receive an additional amount owing to the crisis caused by COVID-19.

- Recommendations have been developed for teachers on how to support the education of children with disabilities who are being homeschooled and how best to support their learning.

It is very important that countries adopt an inclusive response to the pandemic, both during lockdown -ensuring full access to the necessary supplies for life and health - and post-lockdown - guaranteeing the effective exercise of rights such as quality inclusive education and inclusion in the labour market. In this respect, the principles of nondiscrimination, equal opportunities and accessibility established in the Convention on the Rights of Persons with Disabilities are a fundamental pillar in the management of the health emergency, both during the pandemic and in the subsequent recovery phase, especially with regard to health services. 
The following are some specific recommendations resulting from the overview outlined in this document and which have been highlighted in different international forums with the aim of ensuring that countries improve the situation of persons with disabilities:

- Internationally agreed, widely discussed instruments in the process of implementation, such as the Convention on the Rights of Persons with Disabilities, the Montevideo Consensus on Population and Development, and the 2030 Agenda for Sustainable Development, are reference tools for prioritizing measures to ensure that the pandemic has the smallest impact possible on persons with disabilities and that their rights are respected.

- There is an urgent need to promote research on the impact of COVID-19 on the health of persons with disabilities. This requires the following: ensure that priority is given to diagnostic tests for persons with disabilities who have symptoms; identify and remove barriers to treatment, including providing accessible environments in hospitals and in testing and quarantine facilities; and allocate financial resources for these processes.

- Health information and communications must be developed and disseminated through accessible modes, means and formats, and persons with disabilities and their organizations must be actively involved in developing a rights-based response to the pandemic that is inclusive of persons with disabilities in all their diversity.

- With regard to social protection measures, it is essential to ensure the income and consumption of households with persons with disabilities by providing financial assistance to such persons when they have no income. Children, adolescents and young people with disabilities must also have access to basic services, housing, adequate food and education.

- Persons with disabilities must have access to support services to lead safe, healthy and independent lives. If informal caregivers have left formal employment to devote all their time to supporting a relative with a disability, financial assistance programmes should be put in place to cover this lack of household income.

- With regard to workplaces, it is recommended that all necessary protective measures, specific adjustments and accessible environments be implemented to ensure the safety of persons with disabilities who continue to work during the pandemic. Where necessary, employers of persons with disabilities must give them priority to work from home or to be granted paid leave.

- Education institutions must be reopened safely. Until this happens, there may be an opportunity for national education systems to become equitable and inclusive systems. To that end, access to the Internet for distance learning should be guaranteed and software should be made accessible to persons with disabilities, including through the provision of assistive devices and reasonable accommodation. There is a need to provide teachers with guidance, training and support in inclusive education through distance learning, and to design materials that are accessible and adapted to students with disabilities, to support such learning.

- Persons with disabilities have the right to participate fully and effectively in decisions that affect their lives. Putting into practice the motto "nothing about us without us", coined by the initiators of the Convention on the Rights of Persons with Disabilities, there is a need for an inclusive response. At all stages of the response, from planning and design to implementation and monitoring, persons with disabilities and their organizations must be consulted and actively involved. This will help achieve immediate inclusion, enable all COVID-19-related measures to benefit persons with disabilities, and contribute to longer-term development and recovery.

In all the topics discussed in this document, there is an absence or significant deficit of data and information on persons with disabilities. This information is needed to understand the different ways in which persons with disabilities are affected by COVID-19, and to ensure that they are included in all phases of response and recovery. Robust data collection and dissemination systems are essential to ensure disaggregation at the subnational level by disability, age, sex and cause of death. These data should be collected using internationally recognized methods and considering the recommendations of the United Nations Statistics Division as well as of the Washington Group on Disability Statistics and $\mathrm{WHO}$. These recommendations should be reflected in the various data sources: population 
and housing censuses, disability-specific surveys and administrative records, particularly records of persons with disabilities. Information collected over the long term should be disaggregated by gender, age, ethnicity and migration status, as intersectionalities among these vulnerable groups accentuate risks and can create new barriers for persons with disabilities. This information is thus very important to design rights-based social policies for this population group.

\section{Bibliography}

Arriagada, I. (2007), "Familias latinoamericanas: cambiantes, diversas y desiguales", Papeles de Población, vol. 13, No. 53, Toluca, Autonomous University of Mexico State.

Bautista, J. (2013), "El derecho humano al agua y al saneamiento frente a los Objetivos de Desarrollo del Milenio (ODM)", Project Documents (LC/W.536), Santiago, Economic Commission for Latin America and the Caribbean (ECLAC), April.

CDC (Center for Disease Control and Prevention) (2020), "People with disabilities", Atlanta, 11 September [online] https://www.cdc.gov/coronavirus/2019-ncov/needextra-precautions/people-with-disabilities.html.

ECLAC (Economic Commission for Latin America and the Caribbean) (2020a), "Persons with disabilities and coronavirus disease (COVID-19) in Latin America and the Caribbean: status and guidelines", COVID-19 Report, Santiago, April.

(2020b), "Measuring the impact of COVID-19 with a view to reactivation", COVID-19 Special Report, No. 2, Santiago, April.

(2020c), "The COVID-19 pandemic is exacerbating the care crisis in Latin America and the Caribbean", COVID-19 Report, Santiago, April.

_ (2020d), "The social challenge in times of COVID-19", COVID-19 Special Report, No. 3, Santiago, May.

(2019a), "Aspectos conceptuales de los censos de población y vivienda: desafíos para la definición de contenidos incluyentes en la ronda 2020", Seminars and Conferences series, No. 94 (LC/TS.2019/67), Santiago.

__ (2019b), First regional report on the implementation of the Montevideo Consensus on Population and Development (LC/CRPD.3/6), Santiago.

(2019c), Quadrennial report on regional progress and challenges in relation to the 2030 Agenda for Sustainable Development in Latin America and the Caribbean (LC/FDS.3/3/Rev.1), Santiago.

(2019d), Social Panorama of Latin America, 2018 (LC/PUB.2019/3-P), Santiago.

(2018a), Social Panorama of Latin America, 2017 (LC/PUB.2018/1-P), Santiago.

(2018b), Towards a regional agenda for inclusive social development: Bases and initial proposal (LC/MDS.2/2) Santiago.

(2016), The social inequality matrix in Latin America (LC/G.2690(MDS.1/2)), Santiago. (2014), Regional report on measuring disability: overview of the disability measurement procedures in Latin America and the Caribbean (LC/L.3860(CE.13/3)), Santiago.

(2013a), Social Panorama of Latin America, 2012 (LC/G.2557-P), Santiago.

(2013b), Montevideo Consensus on Population and Development (LC/L.3697), Santiago.

(2012), Population, territory and sustainable development (LC/L.3474(CEP.2/3), Santiago. (2010), Time for equality: closing gaps, opening trails (LC/G.2432(SES.33/3)), Santiago.

ECLAC/ILO (Economic Commission for Latin America and the Caribbean/International Labour Organization) (2020), "Work in times of pandemic: the challenges of the coronavirus disease (COVID-19)", Employment Situation in Latin America and the Caribbean, No. 22 (LC/TS.2020/46), Santiago.

ECLAC/PAHO (Economic Commission for Latin America and the Caribbean/Pan-American Health Organization) (2020), "Health and the economy: a convergence needed to address COVID-19 and retake the path of sustainable development in Latin America and the Caribbean", COVID-19 Report - ECLAC-PAHO, Santiago, July. 
ECLAC/UNESCO (Economic Commission for Latin America and the Caribbean/United Nations Educational, Scientific and Cultural Organization) (2020), "Education in the time of COVID-19", COVID-19 Report - ECLAC-UNESCO, Santiago, August.

ECLAC/UN-Women (Economic Commission for Latin America and the Caribbean/United Nations Entity for Gender Equality and the Empowerment of Women) (2020), Care in Latin America and the Caribbean during the COVID-19: towards comprehensive systems to strengthen response and recovery, Santiago, August.

González, D. (2017), "Desigualdades socio demográficas, segregación residencial socioeconómica y su expresión territorial", Indicadores no monetarios de pobreza. avances y desafíos para su medición, P. Villatoro (comp.), Seminars and Conferences series, No. 87 (LC/TS.2017/149), Santiago, Economic Commission for Latin America and the Caribbean (ECLAC), December.

González, D. and M. Stang (2014), "Las personas con discapacidad en América Latina a 20 años de los consensos de El Cairo: la necesidad de información para políticas y programas", Notas de Población, vol. 41, No. 99 (LC/G.2628-P), Santiago, Economic Commission for Latin America and the Caribbean (ECLAC), December.

ILO (International Labour Organization) (2020), "No one left behind, not now, not ever: persons with disabilities in the COVID-19 response", Geneva, April [online] https:// www.ilo.org/wcmsp5/groups/public/---ed_emp/---ifp_skills/documents/publication/ wcms_741287.pdf.

ILO and others (International Labour Organization and others) (2020), "Disability inclusive social protection response to COVID-19 crisis", Geneva [online] https://www.socialprotection.org/gimi/gess/RessourcePDF.action?id=56029.

Meléndez, R. (2019), "Las políticas públicas en materia de discapacidad en América Latina y su garantía de acceso a una educación inclusiva de calidad", Revista Actualidades Investigativas en Educación, vol. 19, No. 2, San José, University of Costa Rica.

OAS (Organization of American States) (2020), Practical Guide to Inclusive and Rightsbased Responses to COVID-19 in the Americas, Washington, D.C.

$\mathrm{OHCHR}$ (Office of the United Nations High Commissioner for Human Rights) (2020), "COVID-19 and the rights of persons with disabilities: guidance", Geneva, April [online] https://www.ohchr.org/Documents/Issues/Disability/COVID-19_and_The_ Rights_of_Persons_with_Disabilities.pdf.

PAHO (Pan American Health Organization) (2020), "Disability considerations during the COVID-19 outbreak", Geneva [online] https://apps.who.int/iris/bitstream/ handle/10665/332015/WHO-2019-nCov-Disability-2020.1-eng.pdf.

Pérez, A. (2016), "Impacto de la discapacidad en el núcleo familiar", Navarre, Public University of Navarre (UPNA) (UPNA) [online] https://academica-e.unavarra.es/ bitstream/handle/2454/23449/TFG_AMAIA\%2OPEREZ\%20AYESA.pdf.

Stang, M. (2011), "Las personas con discapacidad en América Latina: del reconocimiento jurídico a la desigualdad real", Population and Development series, No. 103 (LC/L.3315-P), Santiago, Economic Commission for Latin America and the Caribbean (ECLAC), April.

Ullmann, H. and others (2018), "Information and communications technologies for the inclusion and empowerment of persons with disabilities in Latin America and the Caribbean", Project Documents (LC/TS.2018/48), Santiago, Economic Commission for Latin America and the Caribbean (ECLAC), October.

UN-Habitat (United Nations Human Settlements Programme) (2020), "COVID-19: key messages", Nairobi [online] https://unhabitat.org/sites/default/files/2020/03/ covid19_key_messages_eng_1.pdf.

United Nations (2020a), "Joint statement: local governments and persons with disabilities in relation to COVID-19", New York, 5 May [online] https://sustainabledevelopment. un.org/content/documents/29321jointStatementLocalGovernmentsPWDCovid19.pdf. (2020b), "Joint statement: Women and girls with disabilities and older women in relation to the COVID-19 pandemic", New York, 28 April [online] https://www. un.org/development/desa/disabilities/wp-content/uploads/sites/15/2020/04/ covid19-joint-statement-women-girls-disabilities-olderwomen-covid19.pdf.

(2020c), "Policy brief: COVID-19 in an urban world", New York, July [online] https:// unhabitat.org/sites/default/files/2020/07/sg_policy_brief_covid_urban_world_ july_2020_final.pdf. 
(2020d), "Policy brief: a disability-inclusive response to COVID-19", New York [online] https://unsdg.un.org/sites/default/files/2020-05/Policy-Brief-A-DisabilityInclusive-Response-to-COVID-19.pdf.

(2020e), "Declaración conjunta: el derecho a la vida de las personas con discapacidad y personas mayores infectadas por el COVID-19", New York, April [online] https:// www.un.org/development/desa/disabilities/wp-content/uploads/sites/15/2020/04/ Versi\%C3\%B3n2-Decl-Est\%C3\%A1ndar-Bioet-Dpcd-ES2Oabril.pdf

(2020f), "17 Goals to transform our world", New York [online] https://www.un.org/ sustainabledevelopment/.

(2009), Realizing the Millennium Development Goals for persons with disabilities through the implementation of the World Programme of Action concerning Disabled Persons and the Convention on the Rights of Persons with Disabilities. Report of the Secretary-General (A/64/180), New York.

_ (2006), Convention on the Rights of Persons with Disabilities (A/RES/61/106), New York.

Washington Group on Disability Statistics (2017), The Washington Group Short Set on Functioning: Question Specifications, Washington, D.C., 23 October [online] https://www.washingtongroup-disability.com/fileadmin/uploads/wg/Documents/ Events/17/WG-Document-4-The-Washington-Group-Short-Set-on-FunctioningQuestion-Specifications.pdf.

(2009), Understanding and Interpreting Disability as Measured using the WG Short Set of Questions, Washington, D.C., 20 April [online] http://www.cdc.gov/nchs/ data/washington_group/meeting8/interpreting_disability.pdf.

WHO (World Health Organization) (2020a), Strengthening preparedness for COVID-19 in cities and other urban settings: interim guidance for local authorities, Geneva. (2020b), Disability considerations during the COVID-19 outbreak, Geneva. (2011), World Report on Disability: Summary, Geneva.

This document is part of a series of reports prepared by the Economic Commission for Latin America and the Caribbean (ECLAC) on the evolution and effects of the COVID-19 pandemic in the region. It was prepared by the Latin American and Caribbean Demographic Centre (CELADE)-Population Division of ECLAC, headed by Paulo Saad, under the general coordination of Alicia Bárcena, Executive Secretary of ECLAC.

This document was produced thanks to the cooperation of the Government of Germany through the Federal Ministry for Economic Cooperation and Development (BMZ) and the Deutsche Gesellschaft für Internationale Zusammenarbeit (GIZ).

The boundaries and names shown on the maps included in this publication do not imply official endorsement or acceptance by the United Nations.

Copyright () United Nations, 2021 